"برنامج تدريبى مقترح للوالدين لتنميه مهارات التواصل الاجتماعي

$$
\text { لاى أطفال الروضة المدمجيين" }
$$

باحثة دكتوراة بكلية التربية للطفولة المبكرة - جامعة القاهرة

كبير أخصائيين تنمية مهنية وتقويم مهنى- بالأكاديمية المهنية للمعلم/مدرب معتمد بكانه

يعتبر الامج من أهم الإتجاهات الحديثة في التربية الخاصة، ويركز الامج على خدمة ذوي الإحتياجات الخاصة في بيئاتهم والتخفيف من الصعويات التي يواجهونها سواء في التوافق الاجتماعي

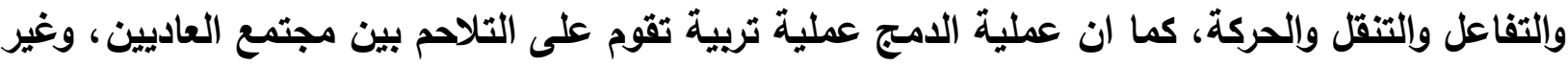

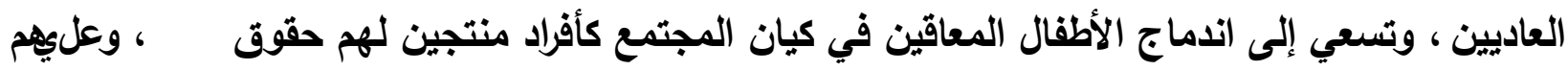

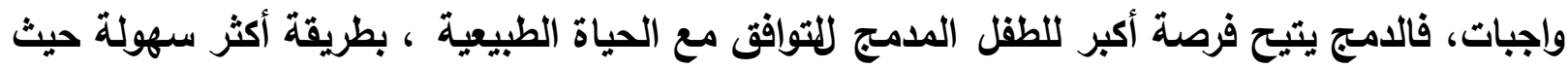

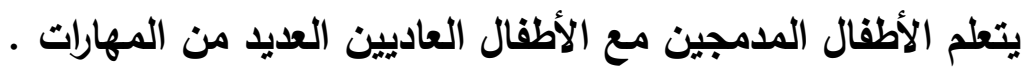
ومن منطلق القزار الوزاري رقم 94 بتاريخ 2009/4/28م والمعدل بالقرار الوزاري رقم 42 بتاريخ الإين

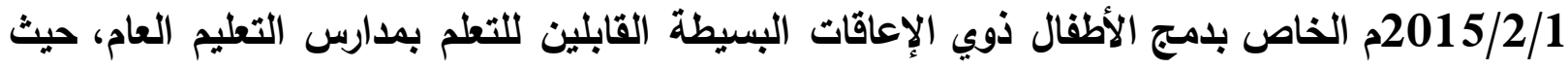

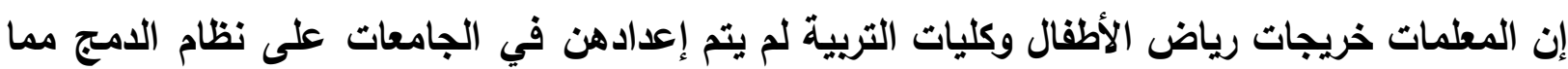

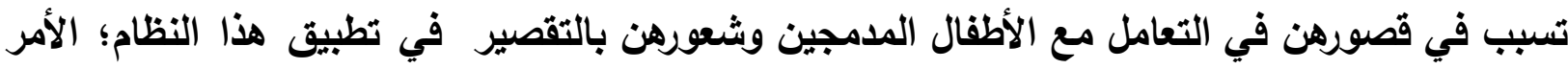
الذي أدى إلى وجود عقبات كثيره تواجه تطبيق الدمج برياض الاض فلعال الأطفال.

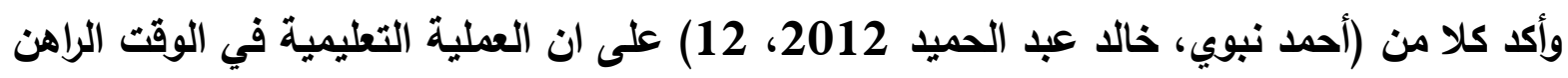

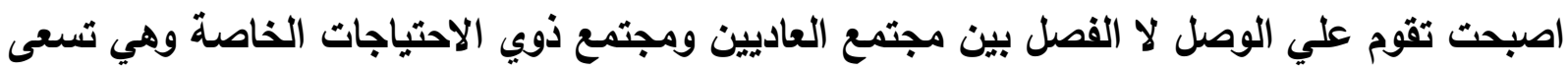
الى توفير مكان ومكانة للمعاق في الروضة والمدرسة.

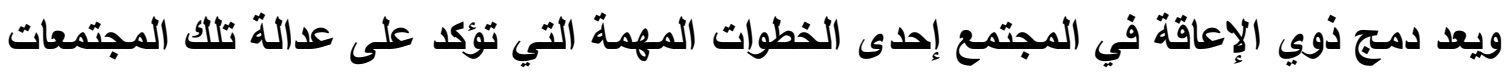
ورقيها وسموها، وفي إطار تمكين الاثخاص ذوي الإعاقة من الإندماج في المجتمع في إطار تفعيل المادة

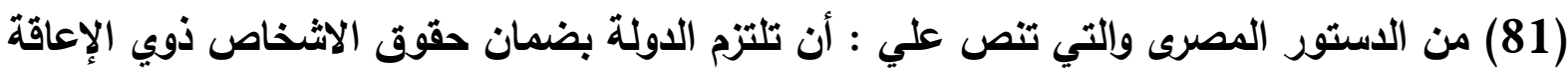

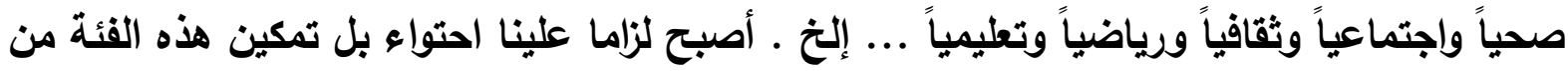

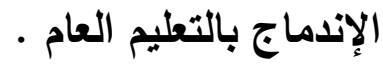

ولكى يتم الامج بهذه الصوره والتى سوف تحسن بالفعل بيئه التعلم لأطفال المدمجيين يجب تضافر

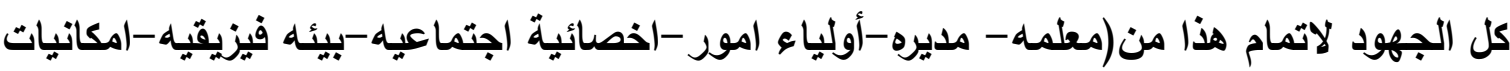
ومستلزمات سوسائل معينه ل... الى اخره). 
ويعتبر دور المعلمه مؤثر وفعال فى توجيه الأطفال وتنميه مهارتهم وملاحظتهم وتدريبهم على المهارات المختلفه وتثمية كثير من المهارت لايههم. وق اشارت منى جاد ( 2004)الى ان طبيعة عمل المعلمات فى رياض الأطفال يستلزم بالضرورة العمل الفريقى، حيت يتعاون معلمتان بشكل فريقى كمرشدين ومستشارين لأطفال وناصحين لهم، فهذا يحقق اقصى استفادة من العملية التعليمية، وهذا ينطبق بكل تأكيا على المعلمات الذين يعملون فى الروضات الدامجة (منى جاد، 2004: 118) واذا كان بالقاعات معلمتان يكمل كلا منهما الاخر فأولياء امور الأطفال المدمجيين والعاديين ايضا شركاء فى انجاح منظومة الامج.

هذا ما يؤكده كوليت (2004) على انه يعتبر أولياء الامور اعضاء الفريق الذين يعرفون عن الطفل ما لا يعرفة احد ولاللك يجب احترامهم وتقديرهم واعتبارهم شركاء فى الفريق، حيث ان لهم الاحقية فى هـ المشاركة فى مراجعة اهداف برامج تعليم ابنائهم، وكذلك عند التخطيط للمرحلة الثاتية.(كوليت دريفت، 2004 : 19: كما تعتبر مشاركة الوالدين اكثر اهمية للعديا من الاسباب، اهمها انهم يعرفون عن الطقل ما لا يعرفه شخص اخر ولألك يستطيعون مساعدة المعلم على فهم الطقل بل ومساعدته فى اكتساب وتتميه المهارات المختلفه اللازمه للطقل. ويشير مارتن هنلى، رويرتا رامزى ( 2004)على انه لابد وان يكون هناك اتصال دائم ومشاركة متكرة بين المعلمين والاباء، فكلما زادت درجة الاندماج والمشاركة الوالدية كلما زاد احتمال نجاح الطقل وتحصيله فى المدرسة (مارتن هنلى، رويرتا رامزى، 2004 :473-

لذا ترى الباحثّه ان دور أولياء امور الأطقال المدمجيين لا يقل أهميه عن المعلمه فكلما زاد فهمهم بأهداف الانشطه بالروضة وكيف تؤثر فى تكوين واثثراء شخصيه أطفالهم كلما كانوا مساعديين وناقليين لهذه الخبرات لأطفالهم ويالتالى تكتمل الاهداف وتتحقق مطالب النمو الى حد كبير لأطفالنا المدمجيين. وهذا يتفق مع دراسة (السيد عبد القادر شريف، 2006) على فاعليه الامج في اكساب الأطفال

المعاقيين القابليين للتعلم العديد من المهارات وان الأطفال المعاقيين اظهروا تحسنا في انماط التفاعل الاجتماعي نتيجه دمجهم مع الأطفال العاديين.، ولكى تتحقق اهداف الدمج لابد من تحسين التواصل من خلال المواقف الاجتماعية. وتتجسد اهميه التواصل للطقل المدمج في الرسائل التى يوجهها الآخرين سواء الأطفال العاديين او المعلمه فهى محاولات للتعبيز عن احتياجاته ورغباته. والتواصل عمليه اجتماعيه نجد فيها ان العلاقه التى تنشا بين الأطفال العاديين والمدمجيين هى مطلبا ضروريا. وقد اكدت العديد من الدراسات على اهميه تنميه مهارات التواصل لاى الأطقال المدمجيين كدراسة عزه عبد الرحمن (2011) التى هدفت الى تنمية مهارات التواصل اللفظى لاى الأطفال المعاقيين باستخدام برنامج لتعليم التواصل اللفظى. لألك لابد من تلديب أولياء امور الأطفال المدمجين على تنميه بعض المهارات الازمة للامج الاجتماعي لأطفالهم مع الأطفال العاديين، حيث تعتبر مهارات التواصل الاجتماعي مدخلا لباقى الانشطه بين الأطفال العادين والمدمجيين. 
مشكلة البحث :

أصبح من المسلم به أن لأطفال التربية الخاصة الحق الكامل في التعليم والمشاركة الفاعلة في

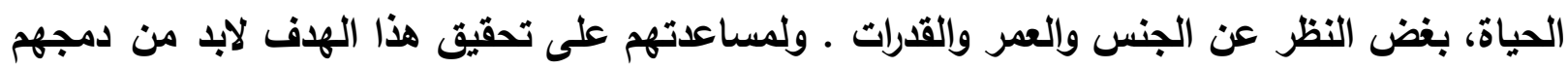

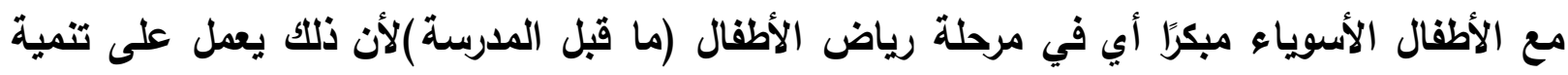

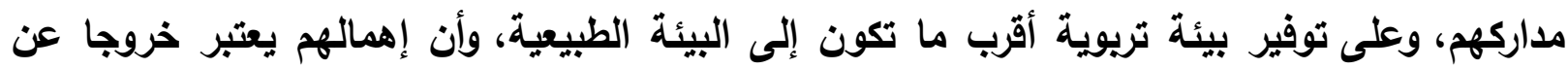

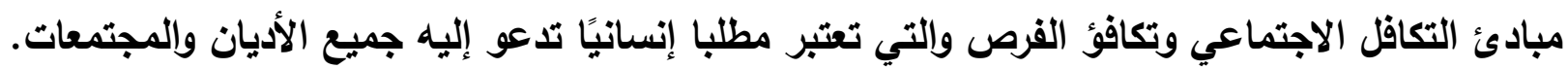

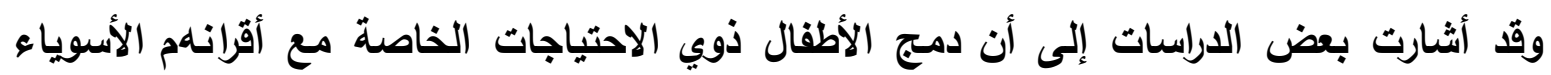
سيساعدهم على تحقيق التوافق الثخصي والاجتماعي من ناحية، وسيغير من ناحية أخرى نظرة الأطفال

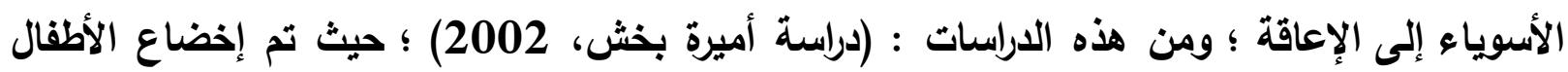

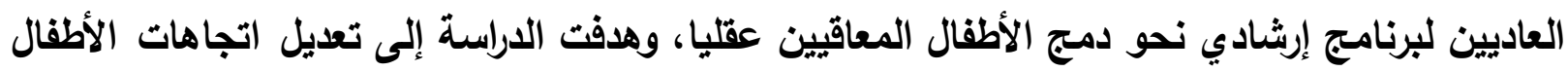

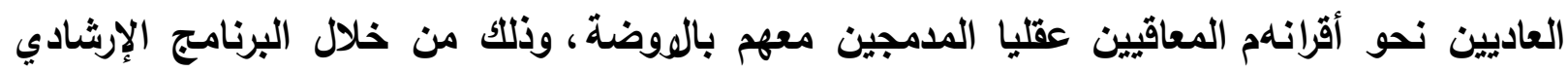

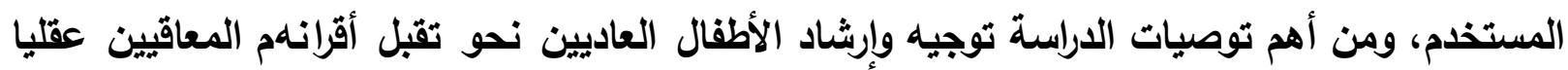
المدمجين معهم وإعداد البرامج الإرشادية التي تعمل على تغيير الاتجاهات العلبية وتدعيم الاتجاهات الايجابية نحو هؤلاء الأطفال.

من خلال الإطلاع على العديد من البحوث والادبيات والدراسات السابقة التي تدور حول الامج كأحد

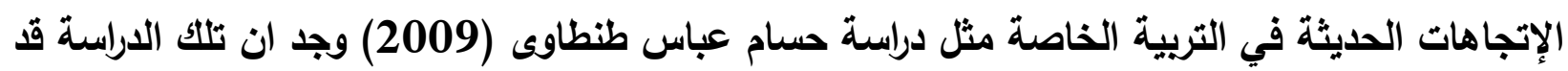

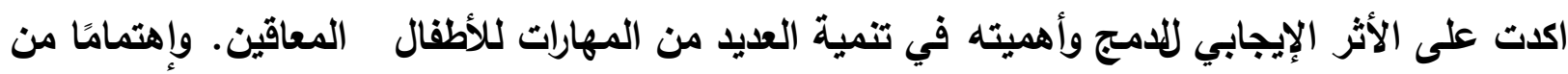

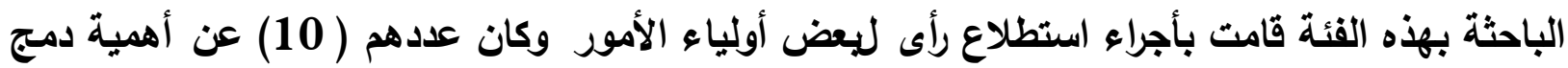

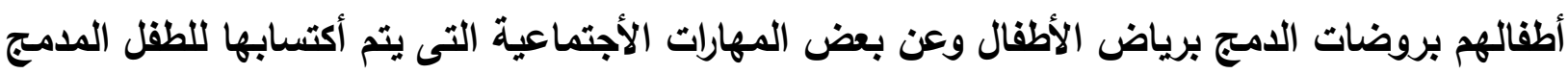
من خلال الأسرة.

وكانت نتيجة استطلاع الرأى التى اجرته الباحثة من خلال إستجابات بعض أولياء الامور انه لا تتوفر لايهه المهارات الكافية عن الامج الاجتماعي لأطفالهم وكيفية التواصل مع الأطفال العاديين. ومن هنا انبثقت فكرة البحث في محاولة (لوضع تصور مقترح لتدريب الوالدين علئ لاعلى كيفيه تنميه بعض مهارات التواصل اللأزمة لأطفالهم المدمجيين مع الأطفال العاديين).

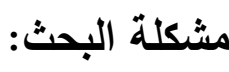
تتحدد مشكلة البحث في السؤال الرئيسى التالى:

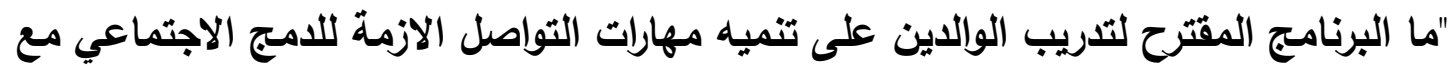
الأطفال العاديين؟ ويتفرع من السؤال الرئيسى الاسئلة الفرعيه التاليه :

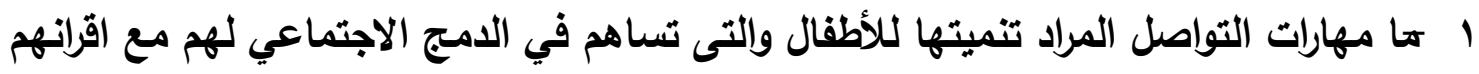


r ما مهارات الأتصال والتواصل التلازمة للوالدين لتنميتها لأطفالهم؟ r ما طبيعة البرنامج التدريبى المقترح للوالدين لتنميه مهارات التواصل لاى أطفالهم المدمجين؟

$$
\text { أهداف البحث: }
$$

ا تحديد بعض مهارات ومجالات التواصل التى يمكن تدريب الوالدين عليها من خلال البرنامج

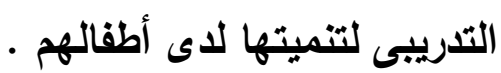

r ب بعداد برنامج مقترح لتديب الوالدين على أكساب الطقل المدمج بعض مهارات التواصل اللازمة للامج الاجتماعي مع الأطفال العاديين.

$$
\text { أهمية البحث: }
$$

• أهمية نظرية : يث يقدم البحث إطاراً نظرياً عن مهارات التواصل المناسبة للامج الاجتماعي للأطفال المدمجين برياض الأطفال. أهمية تطبيقية : تعود الأهمية التطبيقية للبحث إلى تصميم برنامج مقترح للوالدين يساعده م على تنميه مهارات التواصل اللأزمة للامج الاجتماعي لأطفالهم مع الأطفال العاديين . منهج البحث: إستخدمت الباحثة المنهج الوصفي لمناسبته لطبيعة البحث. حدود البحث وعينته:

\begin{tabular}{|c|c|c|c|}
\hline النوع & المكان & اسم المدرسد & مسلسل \\
\hline رسمى عربى & الحى الحادى عشر & على بن ابى طالب & 1 \\
\hline رسمى لغات & الحى العاشر & العاشر التجريبية & 2 \\
\hline رسمى عربى & الحى العاشر & اسامه بن ذيد & 3 \\
\hline رسمى لغات & الحى السادس & التحرير الرسميه & 4 \\
\hline
\end{tabular}
الحدود الموضوعية: اقتصر البحث على تقديم برنامج مقترح لتدريب الوالدين على أكساب الطقل المدمج بعض مهارات التواصل اللأزمة للامـج الاجتماعي مع الأطفال العاديين. الحدود الجغرافية: تم التطبيق على أولياء أمور الأطفال المدمجين ببعض روضات الامج بمحافظة الجيزة (اداره 6 (كتوير).

الحدود البشرية: عينة من أولياء أمور الأطفال المدمجين عددهم (20) ولى امر تم اختيار أولياء الامور المتواجدين اولادهم في الروضات سالفه الأكر وذلك لتواجدهم معا باحد المراكز 
المسائيه الخاصه بتقديم مساعدات لأطفال المدمجين وهذا ييسر على الباحثه الوصول اليهم لتواجدهم بالمركز جميعا مع أطفالهم.

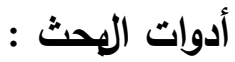
إلمتمارة استطلاع أى أولياء الأمور عن مدى معرفتهم ببعض مهارات التواصل الاجتماعي للطفل المدمج.

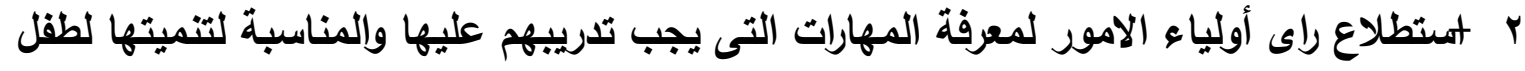

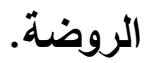

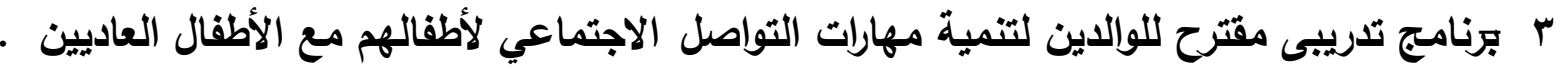
(جميع الأدوات من إعداد الباحثة) مصطحات البحث : أولاً: البرنامجج : (Programe) عرفه عبدالله اسماعيل الصوفي (2000) أنه "مجموعة من الأنشطة يتم تخطيطها و تثمل ما يدور

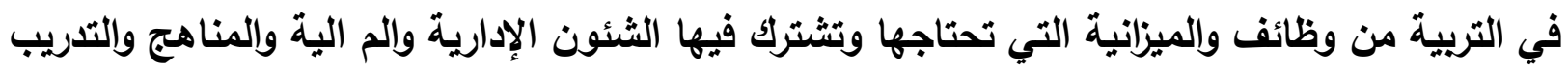

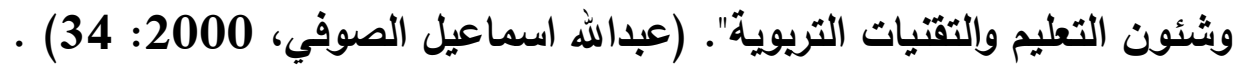
وتعرفه منى جاد ( 2007) بانه "محتوى تريوى منظم يستتد الى فلسفه اجتماعية ونظريات علميه

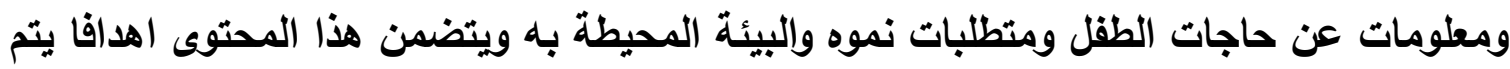

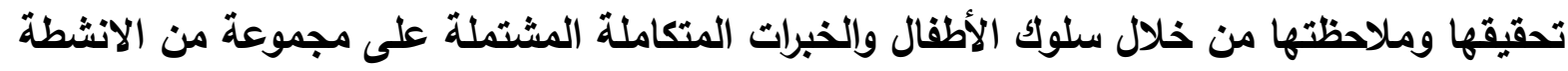
المتنوعة والمتكاملة التى يمارسها الأطفال تحت رعاية المعلمات المتخصصات وياستخدام التقنيات

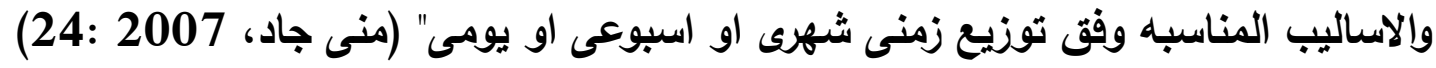

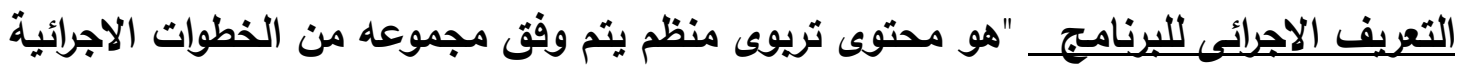
والممارسات العلمية المنظمة ويستند على فلسفة اجتماعية ونظريات علميه واهد ف محددة لأولياء

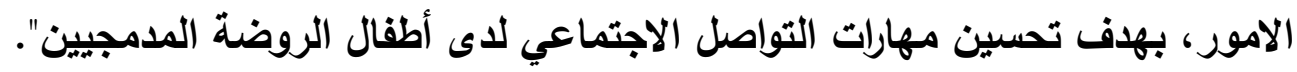

ميارات التواصل: Skills Communication يعرفه حسن شحاته، زينب النجار (2003) بأنها " عملية تبادل الأفكار والأراء والمشاعر بين الأفراد

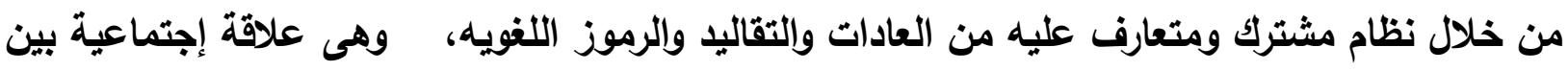

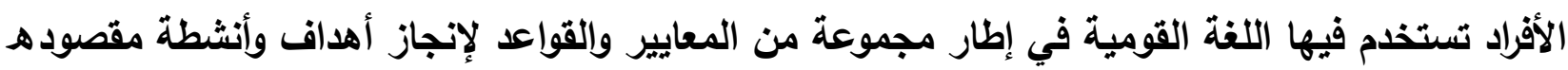

$$
\text { . }
$$

وتعرفه امانى عبد الفتاح ( 2012) بانهاتتلك العمليه التى تتضمن تبادل المعلومات، والمشاعر والافكار، والمعتقات بين البثر والتواصل يتم من خلال الوسائل اللفظية (اللغه المنطوقة المسموعة تبادئ

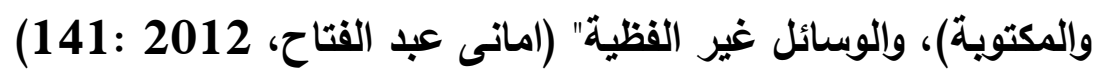
التعريف الإجرائى للتواصل: واسناتير: 
هو تلك العمليه التى تهاف الى نقل وتبادل المعلومات والافكار والمشاعر والعلاقات الاجتماعية من الوالديين الى أطفالهم المدمجيين بهاف تحسيين مهارات التواصل الاجتماعي. : Mainstreaming الدمجن يعرفه بطرس حافظ ( 2009)انه "اختيار انسب الظروف والاساليب التريويه والتعليميه والامكانات

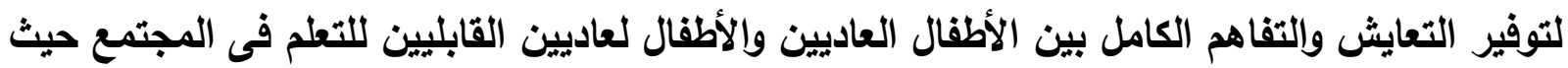
يتقبل كلا منهم الاخر حسب امكانياتهم وحاجاتهم ومتطلبات النمو (بطرس حافظ، 2009: 30) كما عرفته منى جاد ( 2014) بانه "تهج تمكينى يساعد جميع الأطفال على الاستمتاع بطفولتهر والحصول على حقوقهم والمساهمه فى بناعوتغيير مجتمعاتهم "(منى جاد، 2014: 139). التعريف_الإجرائي للادمج:_هو وضع الأطفال ذوى القدرات والإعاقات المختلفه (سمعيه-بصريه- حركيه شلل دماغى) في صفوف تعليميه عاديه مع اقرانهم وتقديم الخدمات التربويه لهم مع توفير دعم صفى الألى كامل ومشاركه وإلايه . ميهاري_الادمجCottrell Inclusion Skills : عرف (1999)(المهارة بانها :القدره على الاداء والتعلم الجيد وقتما نريد. والمهاره نثاط متعلم يتم تطويره خلال ممارسه نثاط ما تدعمه التغذية الراجعة. التعريف الاجرائي لمهارات الدمج :__تعرف مهاره الدمج فى الدراسه الحاليه بانها "مجموعه الأنثطه والمهارات الخاصه بالتواصل الاجتماعي التى يتلقاها الطفل المدمج من والايه فى وجود تغذيه راجعه بغرض تحقيق اغراض الامج بصوره اكثر فاعليه". الإطار النظرى والدراسات السابقة للبحث: أولا : الدمج في رياض الأطفال:

عرفته هلى الناشف بانه "وضع أطفال لهم احتياجات خاصة فى بيئه غير مقيده، حيث يتعلمون ويلقون كل رعايه بطريقه عاديه قر الامكان ".(هدى الناثف، 2005: 147)

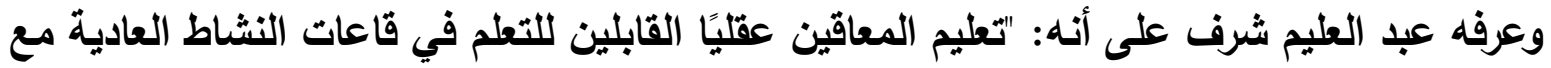

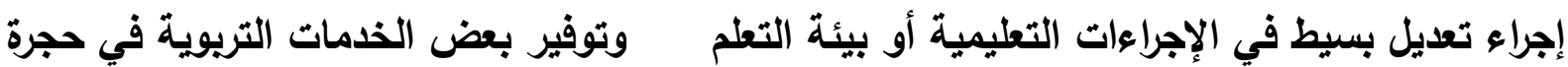

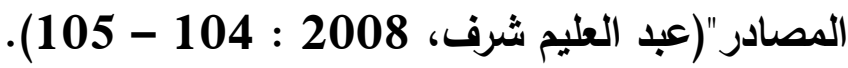

ويعرف(إبراهيم الزهيري، 2007 : 61) الامج بأنه: "يعني بضرورة أن يقضي المعاقون أطول مدة ممكنة في غرف النشاط العادية مع إمدادهم بالخدمات الخاصة إذا لزم الأمر ، كما يعني بضرورة تعديل البرامج التريوية العادية قدر الإمكان بحيث تواجه حاجات المعاقين مع إمداد المعلم العادي بما يحتاج إليه باديه

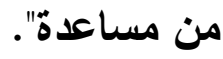
كما عرفته منى جاد( 2014) بانه" نهج تمكينى يساعد جميع الأطفال على الاستمتاع بطقولتهم والحصول على حقوقهم والمساهمة فى بناء وتغيير مجتمعاتهم " . ويقصد به ايضا توفير بيئه تعليميه افضل وصديقه لكل الأطفال تقوم على اساس ان لكل طفل من

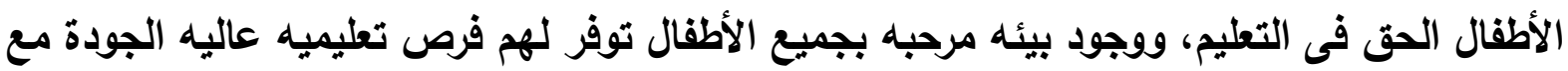


التاكيد على ان وجود فروق فرديه او جسديه او عقلية او تحصيلية لا يعنى مطلقا الحق فى استبعاد اى

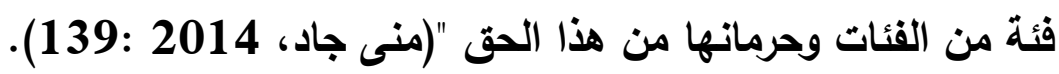

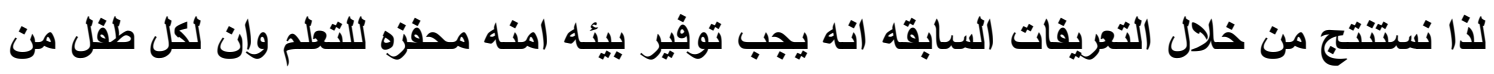

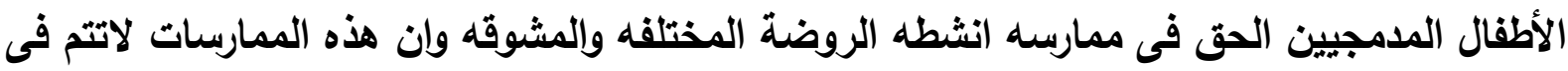

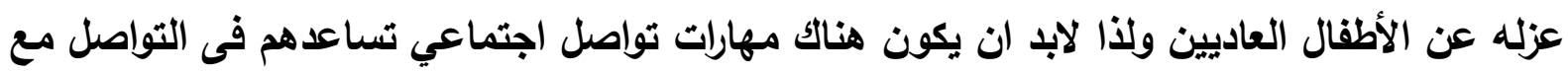

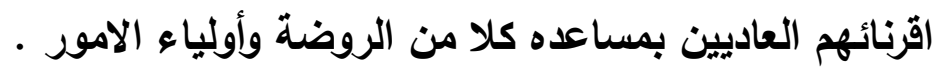

أهمية الامج في رياض الأطفال: - مان

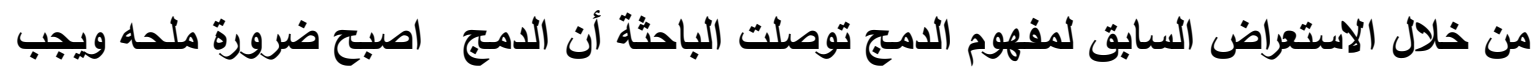

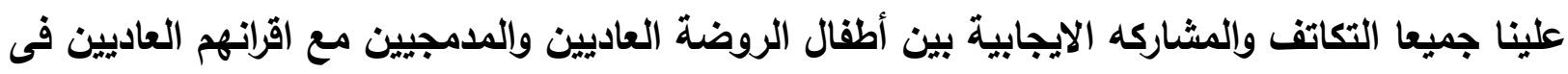

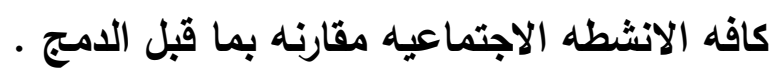

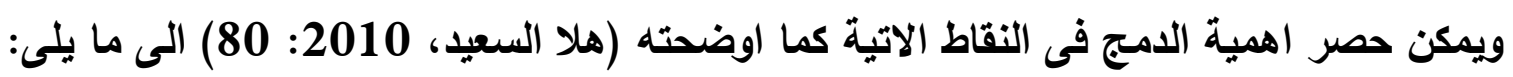

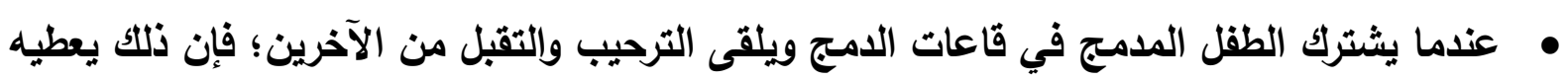
الثعور بالثقة في النفس، ويشعره بقيمته في الحياة ويتقبل إعاقته.

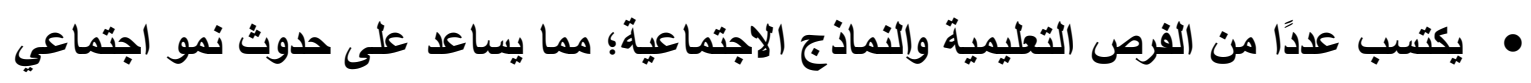

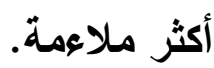
• الامج يمد الطقل بنموذج شخصي، اجتماعي ، سلوكي للتفاهم والتواصل ، وتقليل الاعتماد المتزايد على الأم. هيتمكن الطقل من خلال الامج من تعلم واكتساب العديد من المهارات، ومن تقليد الأطفال الأسوياء بالعديد من السلوكيات، ويثعر الطفل ذوالإعاقة العقلية القابل للتعلم بالمساواة مع الطفل العل العادي.

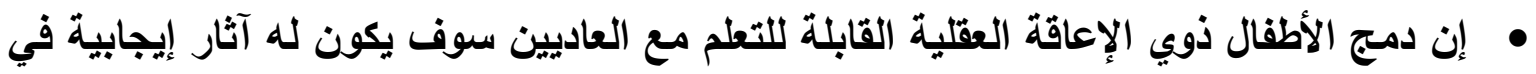
تحسن نفسيته.

يؤدي الدمج إلى تغير اتجاهات الطفل العادي نحو الطفل من ذوي الإعاقة.

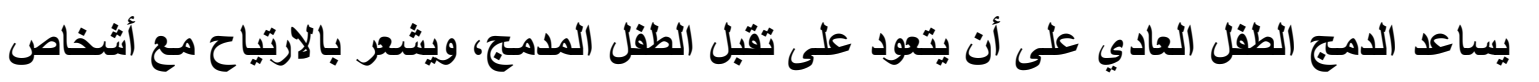
مختلفين عنه.

ومما سبق ترى الباحثه ان وجود الطفل المدمج وسط اقرانة العاديين يكسبه الكثير من المهارات

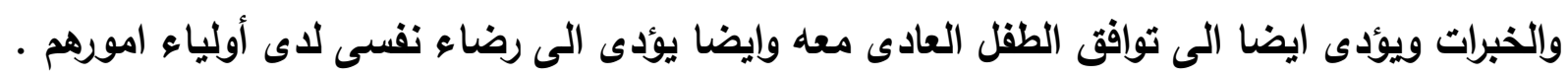

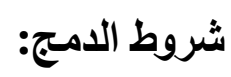
يعتبر الامج من العمليات المعقدة التي تحتاج إلى تخطيط سليم للتأكد من نجاح البرنامج بحيث يكون

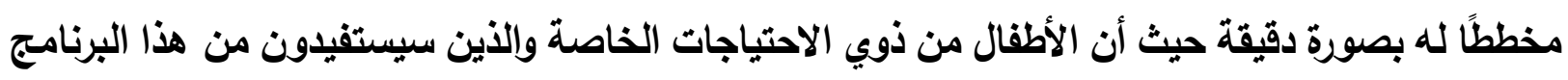

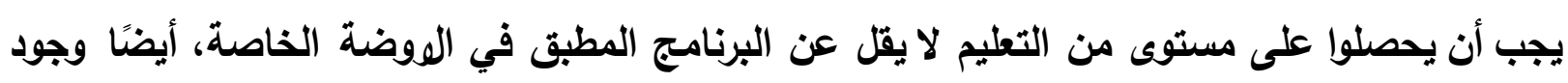


الطفل من ذوي الاحتياجات الخاصة في المدارس العادية لايجب أن يؤثر بأي حال على برنامج المدرسة

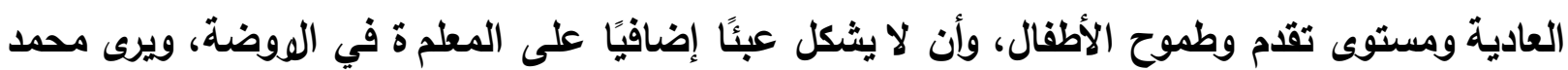

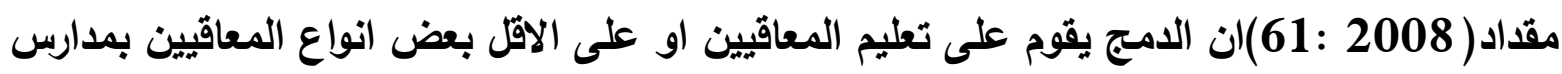

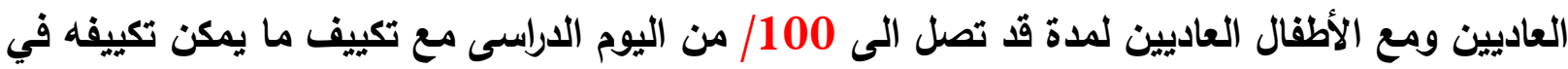
الخطه التريويه لتناسب جميع الأطفال العاديين وغير العاديين. وتحدد ماجدة عبيد (2000: 37) شروط اختيار المعاقيين للامج في النقاط التالية :

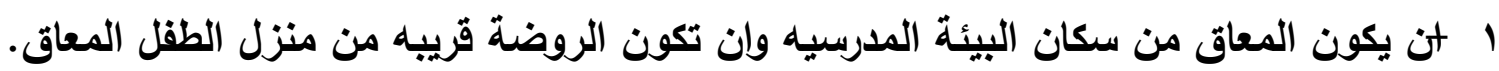

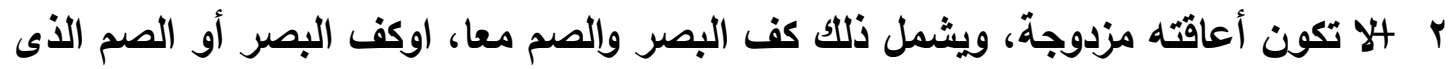

تصاحبة اعاقه ذهنية.

$$
\begin{aligned}
& \text { r با بن يكون المعاق قادر على الاعتماد على نفسه. } \\
& \text { ؛ ثان يتم اختياره بواسطه متخصصون (لجنه الدمج) }
\end{aligned}
$$

ه لا يجوز ان يزيد عدد الأطفال ذوى الاعاقه المدمجيين داخل الفصل على اريعة أطفال.

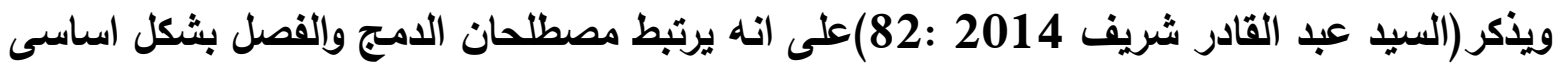
بدرجة الاعاقة فلا يمكن ان نتحدث عن الدمج في حالات الاعاقة الثديده، ولكن يمكن في حالة الاعاقة

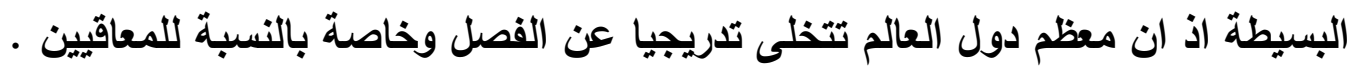

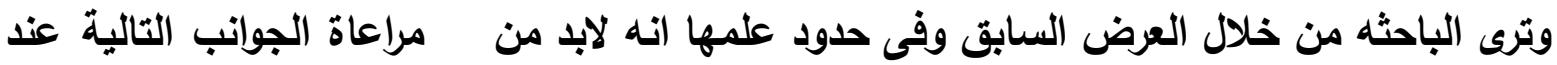

ا بن تعد الييئه الفيزيقية للروضة اعدادا جيدا يؤهلها لأستقبال الأطفال كلا حسب اعاقته مع وجود معينات تساعد هؤلاء الأطفال على التكييف .

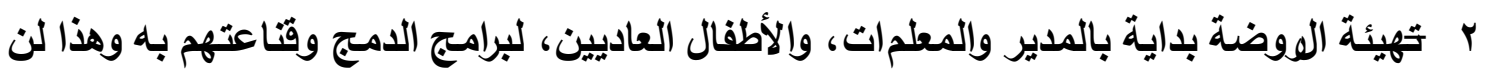
يتم إلا بعد توضيح أهمية الدمج لكل من الإدار ة المدرسية والمعلمات وأولياء والمات أمور الأطفال.

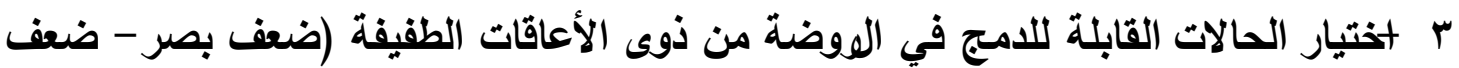

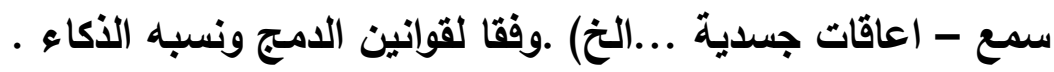
؛ توفير جميع الإمكانيات والاحتياجات المادية والفنية والوسائل التعليمية. ه ت توفير تدريبات متخصصة لجميع الكوادر البشرية من (معلمات - أخصائيين نفسيين - مدربين نطق) 7 الثتهيئه الكامله لأولياء امور الأطفال العاديين لتقبلهم لثقافة الدمج لان هذا سيساعد بدرجه كبيرة في نجاح عمليه الدمج القوانين وكذلك أولياء امور الأطفال المدمجيين .

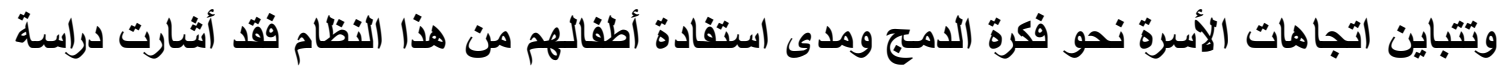
(Punch \& Hyde, 2005)

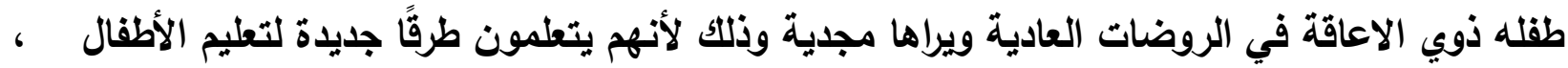


والاعتناء بهم بصفة خاصة ومنهم من يرفض الامج ، ظنا منهم بأن الطقل لن يحظي باهتمام الكافي كما في مدارس التربية الخاصة. وهكذا نجد انه بتوفر شروط الدمج من قوانيين وتثريعات ومعدات ووسائل معينه وتدريبات ونشر

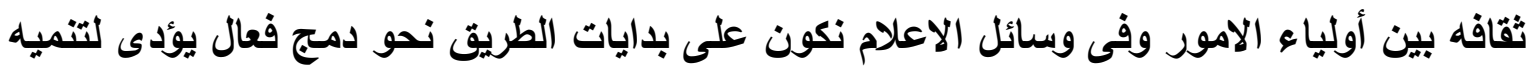

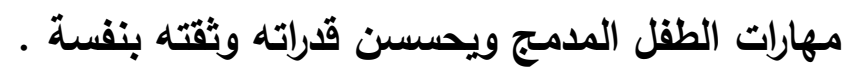

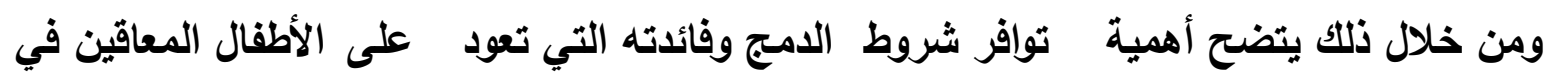

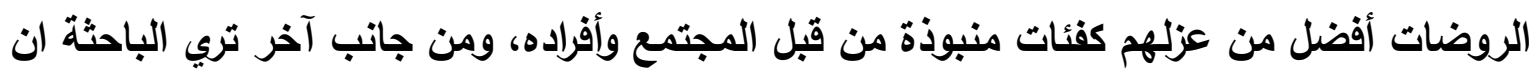

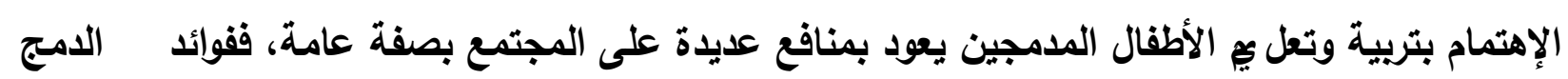

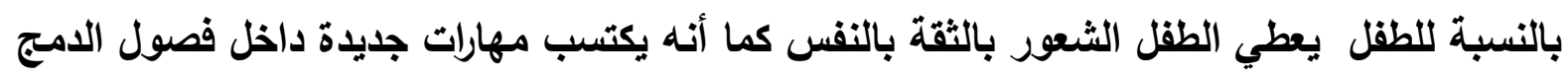
تجعله يفعل الكثير من اجل نفسه كما ان اللعب والعمل مع أطفال آخرين يشجع الطقل المعاق على بلى الكفاح

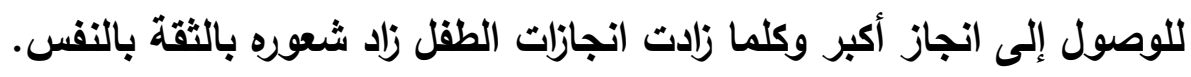

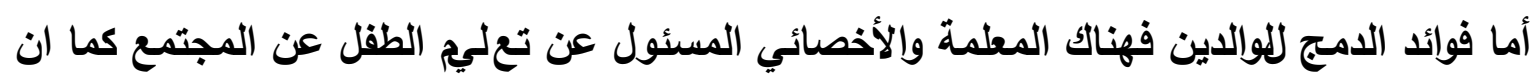

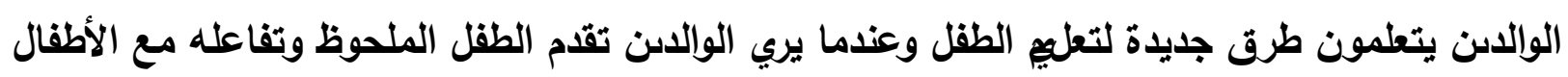

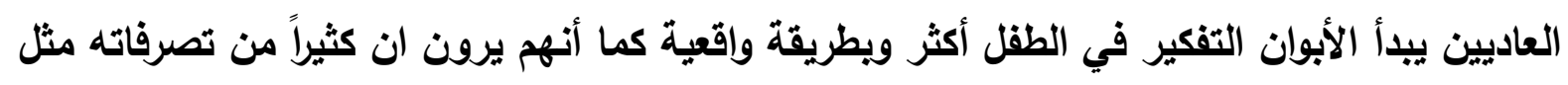

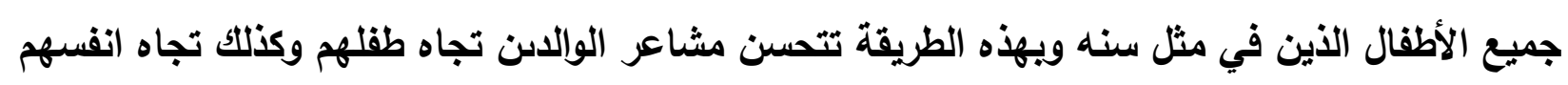
ويالنسبة للامج أهمية على الأسرة من حيث تخليصها من القلق المستمر على أطفالهم وإسعادهم وتقبلهم لوضع أطفالهم، وتخليصهم من الثعور بالاختلاف أو النقص أو القصور .، ولقد وجد الند أن الأطفال العاديين

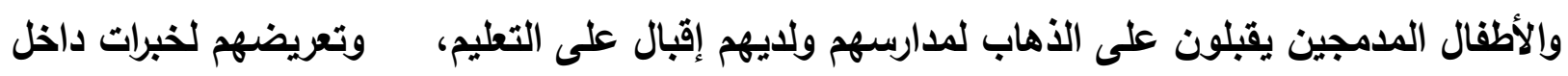

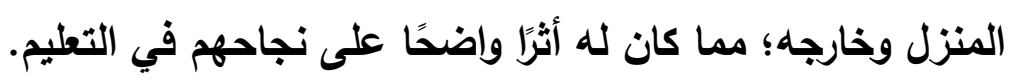

ثانيا : مهارات التواصل اللأزمة للامج الاجتماعي مع الأطفال العاديين: تعريف التواصل:

اثثتقت كلمة تواصل في القاموس المحيط من الفعل "وصل الثئ بالثئ وصلاً". ومعني وصله أي

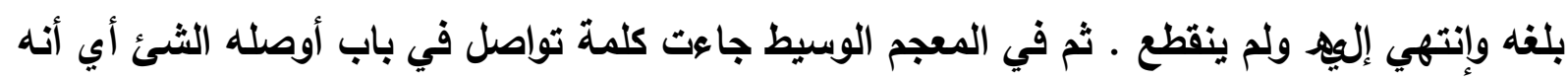

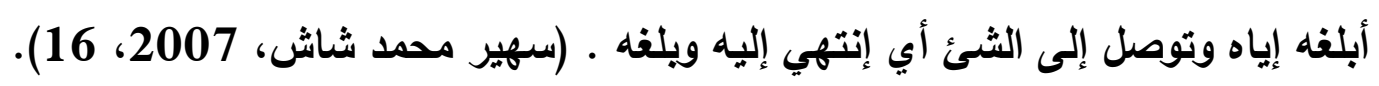
وبشير (كريمان بدير، 2009، 133) أن كلمة تواصل (Communication) مأخوذة من الأصل اللاتيني ( Commumis) بمعني ( Common) أي عام، ذلك لأن الإنسان عندما يتصل بآخر فإنه

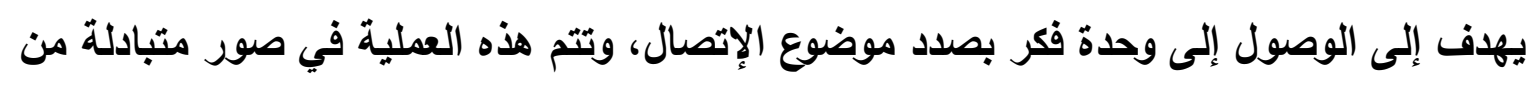
الجانبين لا من جانب واحد بمعني نقل أو إعطاء البيانات والمعلومات إلى الآخرين.

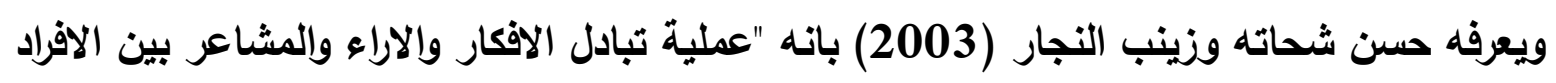

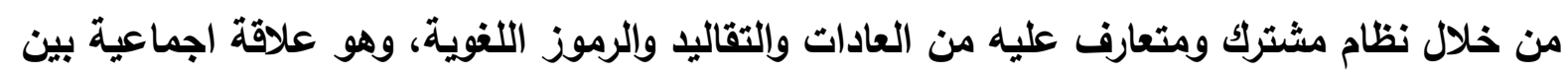


الافراد تستخدم فيها اللغه القومية فى اطار مجموعة من المعايير والقواعد لانجاز اهداف وانشطه مقصودة. (حسن شحاته، زينب النجار، 2003: 33) •

كما عرفه محمد كامل ( 2003) بانه "طريقه او أسلوب لتبادل المعلومات بين الافراد حيث ان المعلومات يمكن ارسالها كما يمكن استقبالها بطرق عديده تتراوح بين الكلمه المنطوفة او المكتوية على ابتسامة صادقة الى حركات اليدين على تعبيرات الوجه ". ويعرفه ايهاب البيلاوى (2005) بانه"تلكك العملية التى تتضمن تبادل المعلومات والمشاعر والافكار والمعتقدات بين البشر، ويتضمن التواصل كلا من الوبائل اللفظية والوسائل غير اللفظية " (ايهاب (البيلاوى، 16: 2005

وتوضح ارينية جوهانسون ( 2009) ان نمو اللغة والاتصال هى عملية مستمرة تبال مع صرخة الطقل الاولى.ويستمر اكتساب اللغه طوال العياة، طالما لاى الفرد قدرة على التعلم، ويعرف الاتصال هنا باعتبارة عمليه يتأثر بواستطها الفرد بشخص او اكثر من الاخرين ليحدث استجابه من نوع ما. فالاتصال فى جوهره عمليه اجتماعية نجد فيها ان العلاقه بين فردين او اكثر هى مطلبا ضروريا. (ارينية جوهانسون، 2009 : 209 وهكذا ومن عرض التعريفات السابقه ترى الباحثه : الى ان التواصل هو:تلك العليه التى يقوم بها الانسان ويتم من خلالها تبادل الافكار والعبارات والمشاعر والاحاسيس وهى ايضا وسيله للتعبير عن حالته النفسية ووسيله للتقدم وتتميه المهارات والقدرات وكلما كاتت مهارات التواصل ومعبره ساعدت الانسان على التعبير عن مشاعرة وافكاره ورغباته وإيضا تكوين قتوات تواصل اجتماعيه فاعله مع الاخريين انواع التواصل : تعنى كلمه "تواصل "نثؤ علاقه حيه متبادلة بين طرفين تهدف لتحقيق اهداف معينة". وإن الأطفال يتطور لايهم مفهوم قصد التواصل قبل اللغة التعبيرية، فهم يتواصلون بواسطة التحديق والحركات والسلوك الصوتي، وتصبح هذه السلوكيات مع التقدم في العمر أكثر نضجاً بإستخدام الكلمات وتوظيف اللغة، بواسطة الالالات اللفظية والتراكيب اللغوية ضمن سياق الكلام، يتعلم الأطفال إستخدام أثكال متعددة آخرى من سلوك التواصل مع محيطهم، فتواصل نظام يتم تعلمه في السياق الاجتماعي · (أل مساعد، العقباوي،

(179،2011

وتثير امانى عبد الفتاح (2012: 142-143) ان هناك نوعيين من التواصل : |

ومن بين الاساليب غير اللفظية تعبير الوجه والايماءات والاشارات وغيرها وكذلك المسافه بين

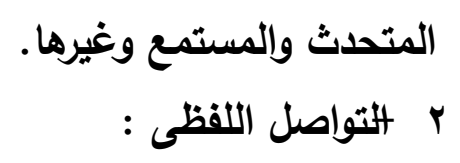


ان التواصل اللفظى اكثر تحديدا من التواصل غيراللفظى، وان الراثدين الأين يستخدمن اللغة يترجمون افكارهم الى كلمات محددة ويربطوها بطريقة تمكنهم من نقل رسائلهم مكتويه او منطوقة وقد شملت دراسة (فلافيا محمد عثمان على، 2012)على نوعين من التواصل وهما التواصل اللفظي والتواصل الاجتماعي حيث هدفت الاراسة من التحقق من فاعلة البرنامج الإرشادي لمعلمات رياض الأطفال في تنمية التواصل اللفظي والاجتماعي وخفض السلوك العدواني لأطفال الروضة . وقد استفادت الباحثه من هذه الدراسه في عمل استطلاع راى أولياء الامور وترتيب المهارات وايضا عمل البرنامج التدريب؟ لأولياء الامور. أهمية التواصل:

تتجسد اهميه التواصل فى محاولات التواصل التى يقوم بها الطقل منذ اللحظه الاولى لميلاده، فأول وجوده يعبر بصرخه، يعبر بها عن نفسه، ثم تتوالى محاولاته فى التعبير عن احتياجاته ورغباته. والتواصل عمليه اجتماعيه نجد فيها ان العلاقة التى تثشا بين الأطفال العاديين والمدمجيين هى مطلبا ضروريا. وقد اكدت العديد من الدراسات على اهميه تنمية مهارات التواصل لاى الأطفال المعاقين ذهنيا كدراسة عزة عبد الرحمن( 2011)التى هدفت الى تنمية مهارات التواصل اللفظى لاى الأطفال المعاقين القابلين للتعلم باستخدام برنامج لتعليم التواصل اللفظى. ودراسة (2011) Stanon-Chapman, Tinal حيث هدفت الى تقييم مهارات التواصل لاى أطفال ما قبل المدرسة مع المعاقيين ودراسه الاثار المترتبة على التواصل الاجتماعي القائم مع الاثران واظهرت النتائج زيادة مستويات التفاعل من قبل الأطفال مع استجابة ايجابية لاقرانهم، وانخفاض مستويات من

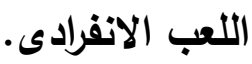

كما تتمثل أهمية التواصل في إثباع الفرد حاجاته الأساسة البيولوجية والتفسية . ، تحقيق مشاعر الانتماء لجماعة ما أو لمجتمع ما، تمكن عملية التواصل الفرد من تحقيق ذاته وتأكيدها في تفاعله مع الآخرين من خلال التعبيرعن ذاته ومشاعره وإحتياجاته وقيمه وإتجاهاته . وينمي التواصل المهارات اللغوية المسموعة والمقروءه وأيضاً المهارات الإجتماعية، معرفة الاتات وحسن تقديرها، النجاح في الحياة وذلك من خلال دور التواصل في مساعدة الشخص على تحقيق أهدافه.

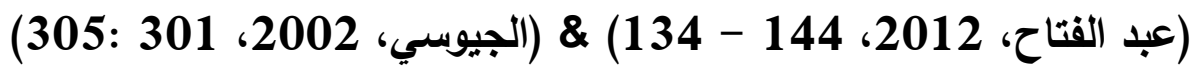
وأوضح(تيملر 2007 (أن التواصل الاجتماعي يتضمن(التعاون مع الآخرين) ويتم أكتساب الأطفال المهارات الإجتماعية ومنها التعاون من خلال الانشطة الحركية والتي تعتمد على الخبرة المباشرة والتجريب في مجموعات تعاونية من الأطفال حيث يكتسبوا من خلال أسس التواصل الاجتماعي والعمل التعاونى.، ويمكن من خلال الانشطة الجماعية التي تبتعد عن المنافسة وتركز على التعاون ان تعمم مهارات التواصل الاجتماعي لطقل ما قبل المدرسة في مواقف اللعب المختلفة داخل القاعة. 
ا بالتعبير عن حاجاته الاساسية وإلنفسيه .

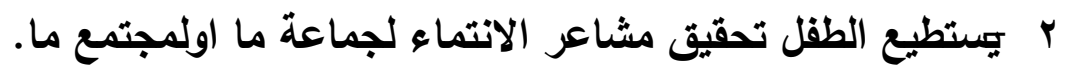

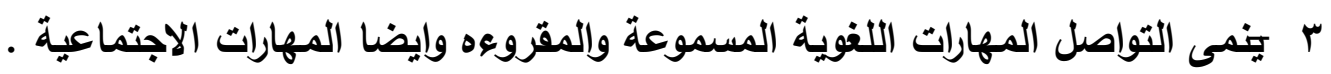
ع معرفة الذات وحسن تقديرها وتقوية الروابط الاجتماعية .

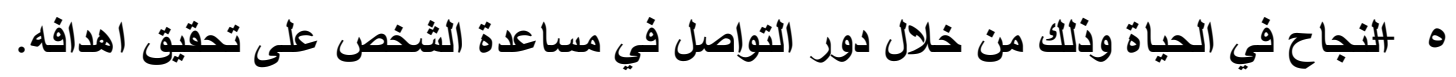
و تحسين الصحه النفسية والجسمية .

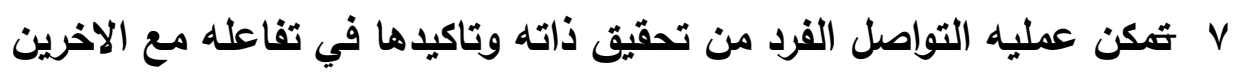

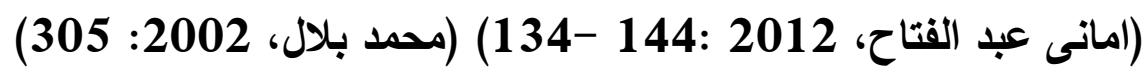
وترى الباحثه ومن خلال عرض الدراسات السابقه والتى تتناول أهمية التواصل بين الأطفال العاديين

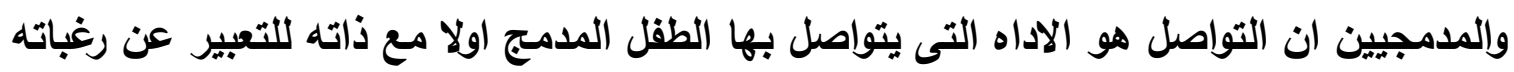

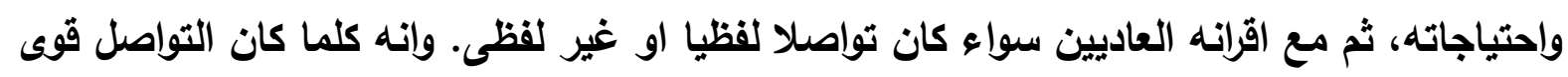

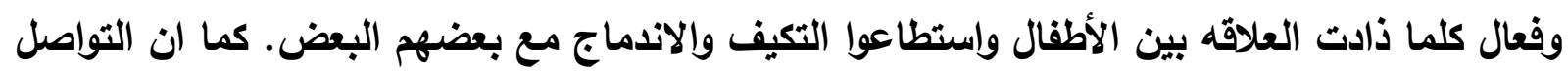

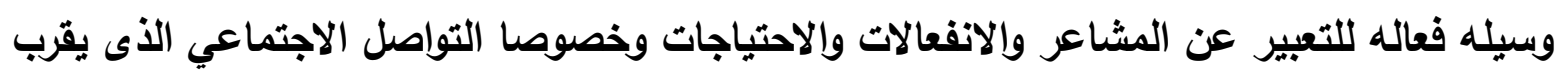

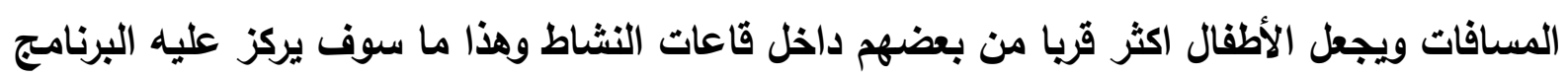

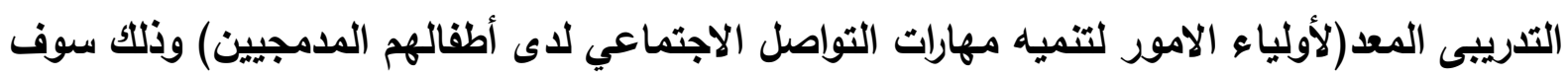

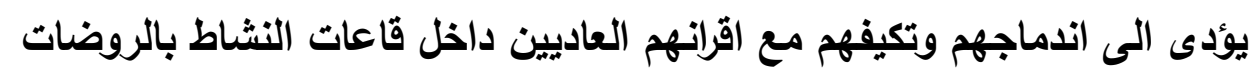

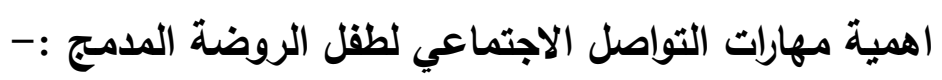
عرف كلا من فرانك وكونور (Frankel \& Connor'O, 2006) مهارات التواصل الأجتماعي بانها هى تلك القدرات الخاصة التي تجعل الطقل قادراً على الأداء بكفاية في أعمال اجتماعية خاصة

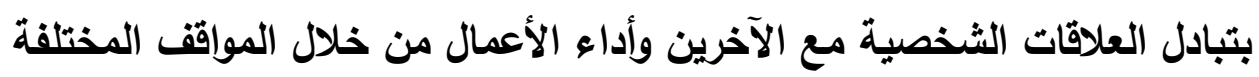

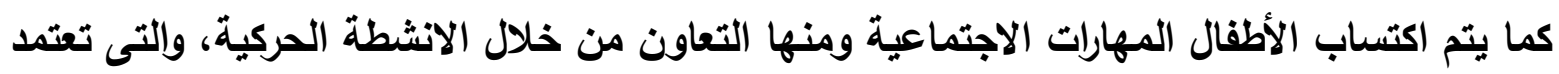

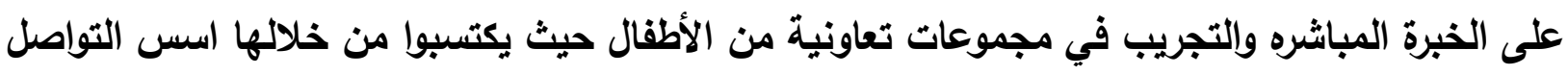
الاجتماعي والعمل التعاونى (Jody,2010,1) ويمكن من خلال الانشطة الجماعية التى تركز على التعاون ان تعم مهارات التواصل الاجتماعي.

(timler vogler-mcgill,2007:167-181) واثشارت كلا من(منى جاد، نجلاء عبد الحكيم،

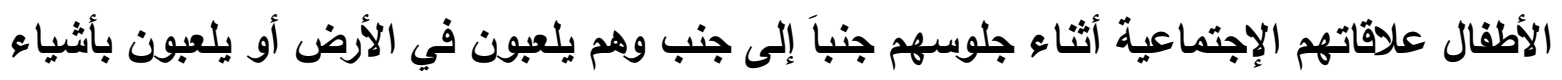

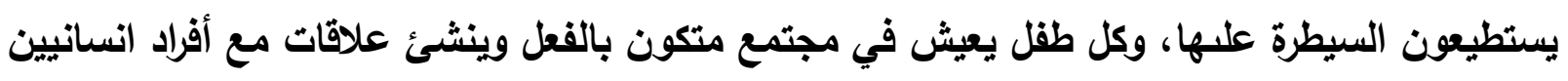

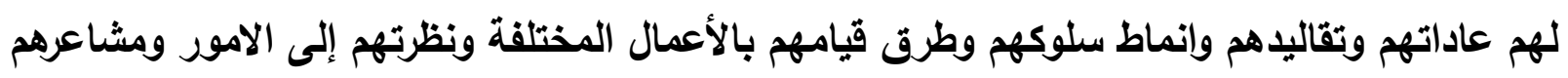

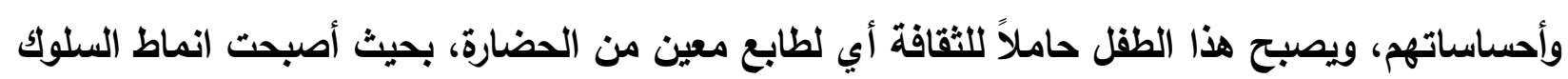


والعادات والتقاليا وطرق التفكير الموجوده في المجتمع خاصة به هو وأصبح يعمل ويفكر ويري الأشياء ويشعر بما حوله بطرق يشترك فيها مع غيره من افراد المجتمع . وأوضح (أنسى قاسم، 2005، 69: 71) أن الأطفال يحتاجون إلى التدعيم والتغذية المرتجعة أثناء محاولاتهم الاولي لإجراء واقامة الإتصال، وان الأطفال يبحثون بشكل نشط عن علاقات بين الموضوعات والأحداث والناس في عالمهم والسلوكيات الصوتية للقائمين على رعايتهم، وقد أثشارت دراسة Forstad) \& Pijl, 2007) المتخلفين عقلياً القابلين للتعلم في الامج الاجتماعي • وقد توصلت الدراسة إلى ان التدريب على المهارات الإجتماعية مدعم أساس لتواصل هؤلاء الأطفال وإقامة علاقات وصداقات ناجحة مع أقرانهم العاديين في • - مل نظام الدمج وتوصلت نتائج دراسة (أمل محمد زكريا، 2015) إلى وجود فروق ذات دلالة إحصائية بين متوسطات رتب درجات أطفال المجموعة التجريبية العاديين والمعاقين عقلياً القابلين للتعلم في روضات الدمج في القياسيين القبلي والبعدي للبرنامج علي مقياس تحسين التواصل لصالح القياس البعدي، وتحسنت مهارات التواصل بين الأطفال العاديين والمدمجين من ذوى الأعاقة العقلية البسيطة . وقد اوضحت نتائج (دراسة غفراء محمد ابراهيم الغتدوري، 2010) الدور الإيجابي للامج في تنمية العديا من المهارات الإجتماعية للمعاقين عقلياً القابلين للتعلم حيث هدفت الدراسة إلى القاء الضوء على أثر الإلتحاق بمدارس الامج في تنمية المهارات الإجتماعية عند الأطفال المعاقين عقلياً القابلين للتعلم وهي تلك المهارات التي تم الإثارة إليها في مشكلة الاراسة ـ والوصول إلى تحديد دقيق لاور كل من مدرسة العزل ومدرسة الامج في إكتساب المعاق عقلياً القابل للتعلم المهارات الإجتماعية التي تسمح لله بالحياة الكريمة في المجتمع حتي يتمكن من الاستفادة بهذه النتائج عند مقارنة هذين النظامين بعد ذلك ، وق ظهر أتجاة المنظور التكاملي للمهارات الاجتماعية فينظر إلى المهارات الاجتماعية باعتبارها عملية تفاعلية بين الجوانب السلوكية (اللفظية وغير اللفظية والجوانب المعرفية والانفعالية الوجدانية في سياق التفاعل الاجتماعي). إجراءات البحث الميدانية: أولا :عينة البحث: تم اختيار عينة من أولياء امور الأطفال المدمجين عددهم (20)، وطبق عليهن استطلاع إى للتعرف على ما لايهن من مهارات للتواصل الاجتماعي للأطفال المدمجين.

1) استطلاع لاى أولياء الامور لمعرفة المهارات التى يجب تدريبهم عليها والمناسبة لتنميتها لطقل

الروضة المدمج.(ملحق رقم 1) أ - صدق استطلاع راى: 
وقد جري التحقى من صدق الاتساق الاخلي لإستطلاع الراى بحساب معامل ارتباط بيرسون بين متوسط كل محور والمتوسط الكلي للفقرات، وذلك باستخدام البرنامج ( SPSS اصدار 21)، والجدول التالي يوضح معاملات الارتباط بين متوسط كل محور والمتوسط الكلي للفقرات : جدول (1)

معاملات الارتباط بين متوسط كل محور والمتوبط الكلي للققرات

\begin{tabular}{|c|c|c|}
\hline مستوي الدلالة & معامل الارتباط & المحاور \\
\hline 0,000 & $* * 0,751$ & المحور الاول \\
\hline 0,000 & ${ }^{* *} 0,749$ & المحور الثاني \\
\hline 0,000 & ${ }^{* *} 0,850$ & المحور الثالث \\
\hline 0,000 & **0,894 & المحور الرابع \\
\hline 0,000 & ${ }^{* *} 0,893$ & المحور الخامس \\
\hline
\end{tabular}

**Correlation is significant at 0.00 level (2- tailed)

ومن نتائج الجدول السابق نجد ان جميع معاملات ارتباط بيرسون معاملات ثبات مقبولة ودالة احصائيا عند مستوي دلالة اقل من (0,001) حيث كان الحد الادني لمعاملات الارتباط (0,749) فيما كان الحد الاعلي(0,894)، وعليه فان الباحثة قد تاكدت من صدق الاتساق الداخلي للاداة ويذلك اصبحت الاداة صالحة للتطبيق علي عينة الدراسة الاساسية. ب - ثبات استطلاع راى: لقياس مدي ثبات اداة الدراسة استخدمت الباحثة (معادلة الفا كرونباخ) للتاكد من ثبات اداة الدراسة علي عينة استطلاعية مكونة من( 10) وقد تم استبعادها من العينة الكلية، والجدول رقم ( 2) يوضح معامل ثبات اداة الدراسة :

جدول (2)

معامل ثبات اداة الاراسة

\begin{tabular}{|c|c|c|c|}
\hline الصدق & ثبات المحور & عدد العبارات & المحاور \\
\hline 0,918 & 0,843 & 5 & المحور الاول \\
\hline 0,884 & 0,783 & 5 & المحور الثاني \\
\hline 0,920 & 0,847 & 5 & المحور الثالث \\
\hline 0,923 & 0,852 & 5 & المحور الرابع \\
\hline 0,914 & 0,837 & 5 & المحور الخامس \\
\hline 0,978 & 0,958 & 25 & الثبات العام للاداة \\
\hline
\end{tabular}

يتضح من الجدول رقم ( 1) ان معامل الثبات العام لمحاور الاراسة مرتفع حيث بلغ ( 0,958) لاجمالي فقرات الاداة الخمسة والعشرون، فيما تراوح ثبات المحاور ما بين ( (0,852) كد اعلي، وهذا يدل علي ان أستطلاع الراى يتمتع بلرجة عالية من الثبات يمكن الاعتماد عليه في التطبيث الميداني للاراسة بحسب مقياس نانلي والذي اعتمد (0,70) كد ادني للثبات. r) برنامج تدريبى مقترح للوالدين يساعده م على أكساب الطقل مهارات التواصل اللأزمة للامج الاجتماعي مع الأطفال العاديين. 
ويتضمن البرنامج المقترح مقدمة واهداف البرنامج المقترح وأهميته وفلسفة بناء البرنامج المقترح

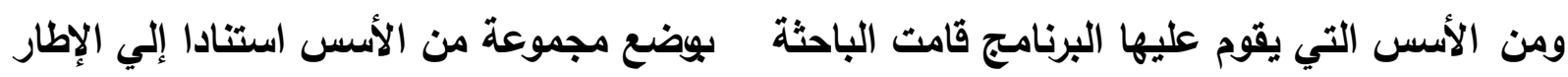

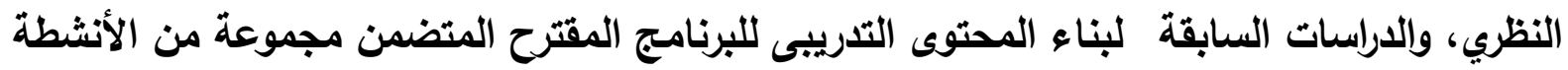

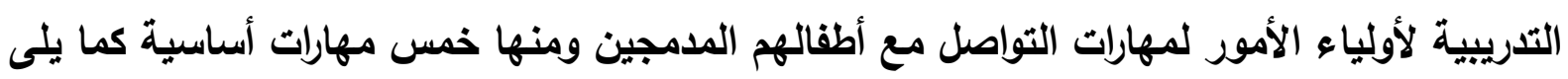

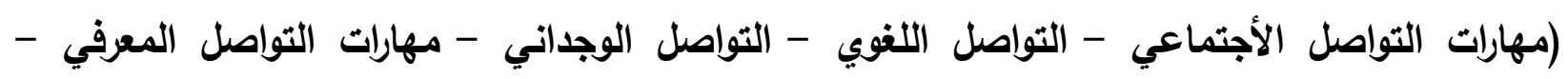
مهارات تعديل سلوكيات الأطفال المدمجين السلبية بالمنزل ). وتضمن البرنامج بعض الأساليب والأستراتيجيات التدريبية المستخدمة فى البرنامج. ثانيا :أساليب المعالجة الأحصائية : أستخدمت الباحثة بعض الأساليب الإحصائية لمعالجة بيانات البحث وهي: الأبي:

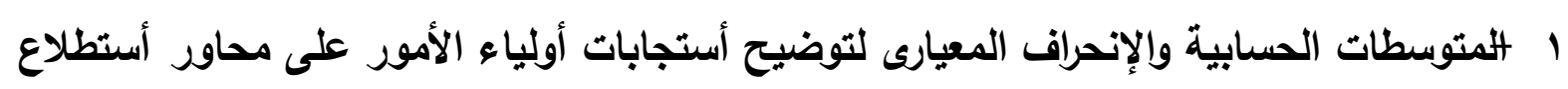
الراى.

r ب إمتخدام معامل الارتباط " لبيرسون Pearson " لحساب معامل الصدق.

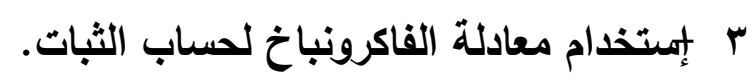
نتائج البحث وتفسبرها :

فيما يلي سوف تعرض الباحثة نتائج البحث وتفسيرها، وذلك من خلال ربطها بتساؤلات البحث، وتقديم توصيات البحث، ويمكن توضيح ذلك فيما يلي:

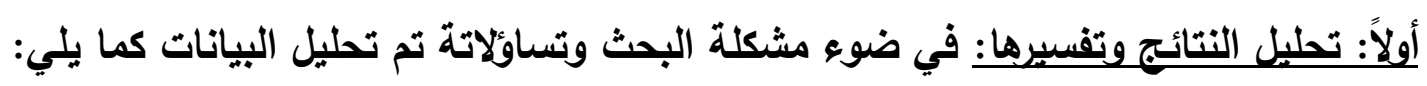

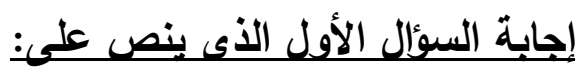
ما مهارات التواصل المراد تنميتها للأطفال والتى تساهم في الامج الاجتماعي لهم مع اقرانهم العاديين

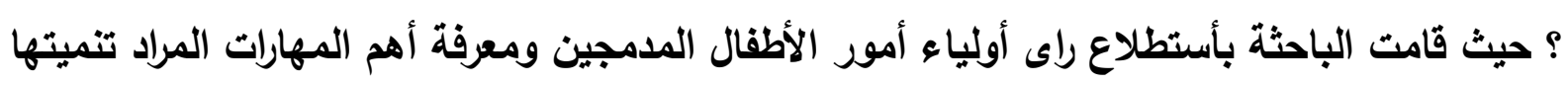

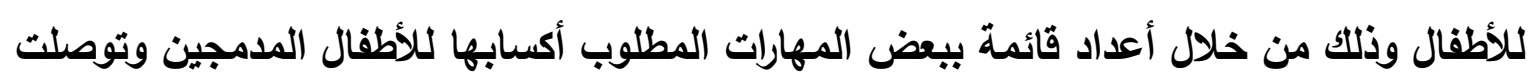

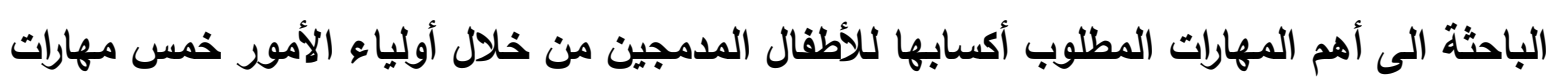
أساسية كما يلى (مهارات التواصل الاجتماعي - التواصل اللغوي - التواصل الوجداني - مهارات التواصل المعرفي - مهارات تعديل سلوكيات الأطفال المدمجين السلبية بالمنزل).

إجابة السؤال الثانى الذى بنص على:

ما مهارات الأتصال والتواصل اللازمة للوالدين لتنميتها لأطفالهج؟

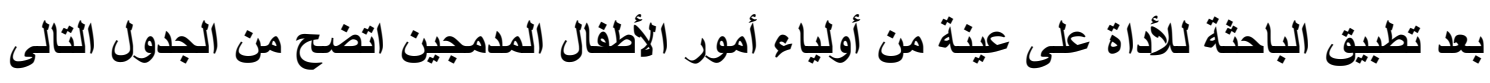

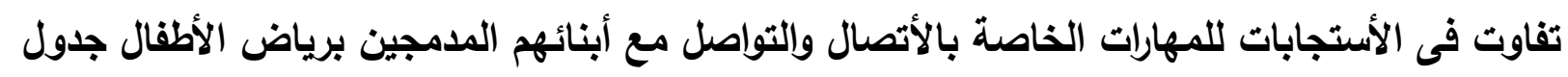

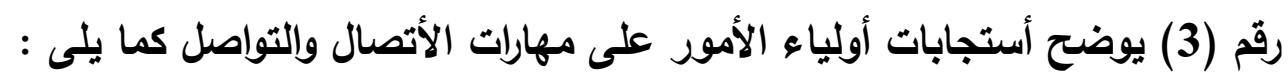


جدول (3)

المتوسط الحسابى والأنحراف المعيارى لإستجابات أولياء الأمور على محاور الأستبيان

\begin{tabular}{|c|c|c|c|c|c|c|c|}
\hline النتيجة & الاتحراف المعياري & المتوسط & 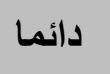 & احيانا & 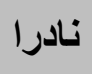 & المقياس & المحاور \\
\hline \multirow{2}{*}{ احيانا } & \multirow{2}{*}{0,57} & \multirow{2}{*}{1,91} & 17 & 47 & 36 & "تكرار & \multirow{2}{*}{ التواصل الاجتماعي } \\
\hline & & & 17 & 47 & 36 & نسبة & \\
\hline \multirow[b]{2}{*}{ احيانا } & \multirow{2}{*}{0,49} & \multirow{2}{*}{2,01} & 11 & 52 & 37 & تكرار & \multirow{2}{*}{ التواصل اللغوي } \\
\hline & & & 11 & 52 & 37 & نسبة & \\
\hline \multirow[b]{2}{*}{ احيانا } & \multirow{2}{*}{0,48} & \multirow{2}{*}{1,69} & 8 & 53 & 39 & تكرار & \multirow[b]{2}{*}{ التواصل الوجداني } \\
\hline & & & 8 & 53 & 39 & نسبة & \\
\hline \multirow{2}{*}{ احيانا } & \multirow{2}{*}{0,52} & \multirow{2}{*}{1,8} & 13 & 55 & 32 & تكرار & \multirow{2}{*}{ التواصل المعرفي } \\
\hline & & & 13 & 55 & 32 & نسبة & \\
\hline \multirow{2}{*}{ احيانا } & \multirow{2}{*}{0,54} & \multirow{2}{*}{1,7} & 14 & 44 & 42 & تكرار & \multirow{2}{*}{ تحديل سلوك } \\
\hline & & & 14 & 44 & 42 & نسبة & \\
\hline
\end{tabular}

بعد دراسة الجدول السابق لنتائج الذمس محاور اتضح انهم جميعا حصلوا ما بين (1,67) إلى

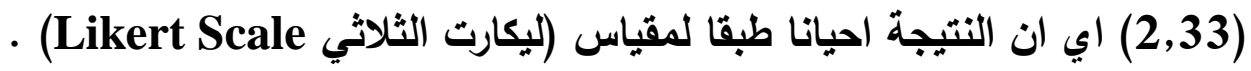

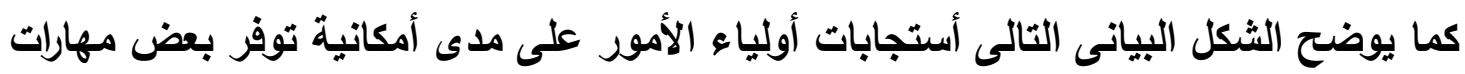
الأتصال والتواصل مع أطفالهم المدمجين برياض الأطفال.

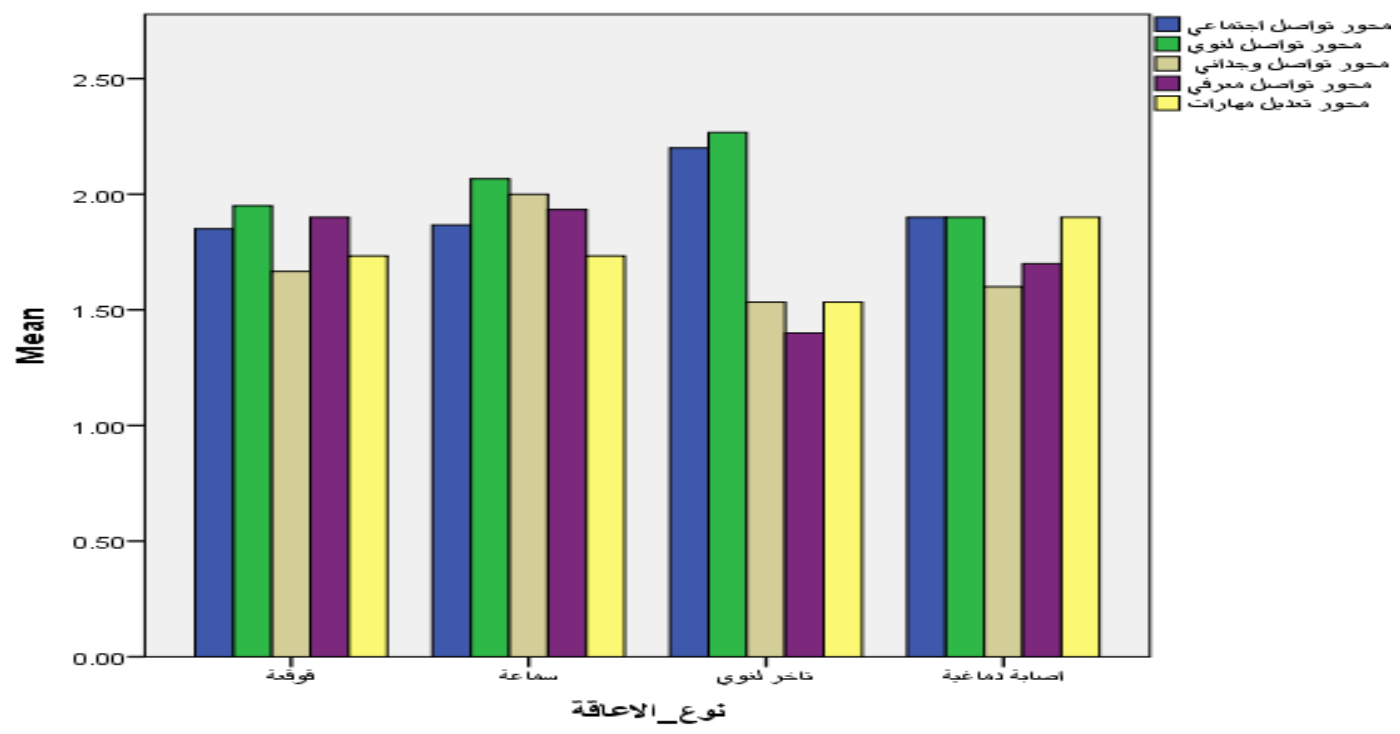

ومن نتيجة ذلك اتضح ان اغلب مهارات الاتصال والتواصل اللازمة لأولياء امور الأطفال المدمجين

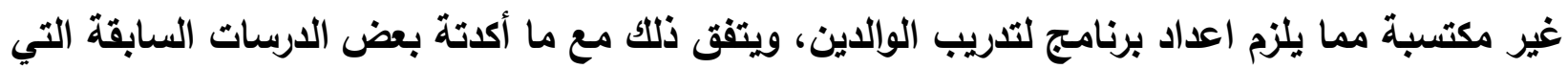

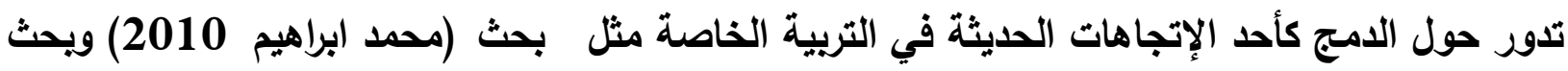

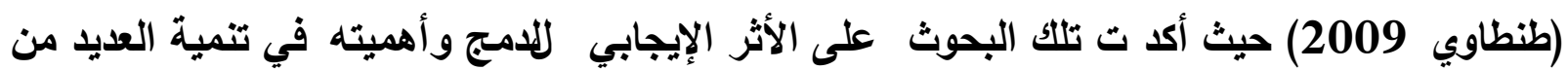

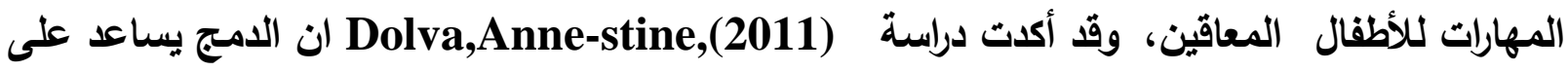




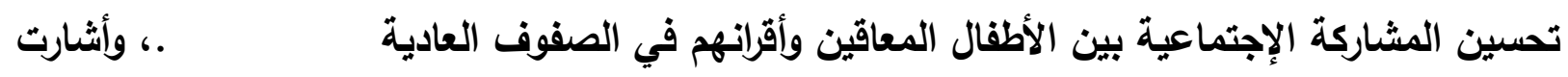

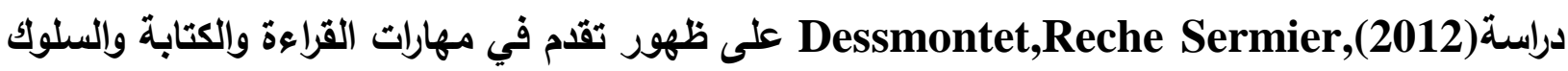
التكيفي لدى الأطفال ذوي الإعاقة الذهنية العدمجين مع أقرانهم العاديين .، ولقد وجد أن الأطفال العاديين

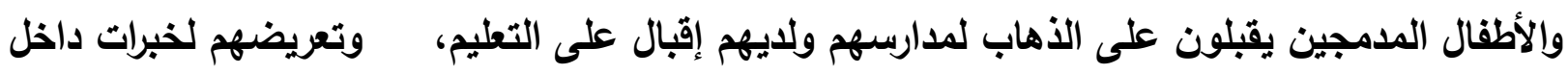

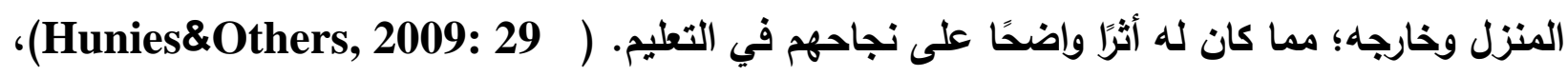

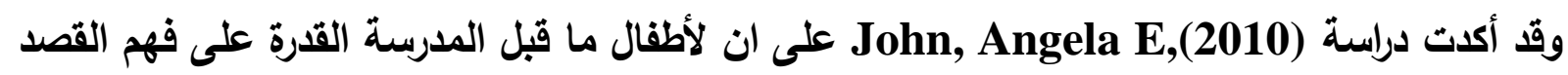

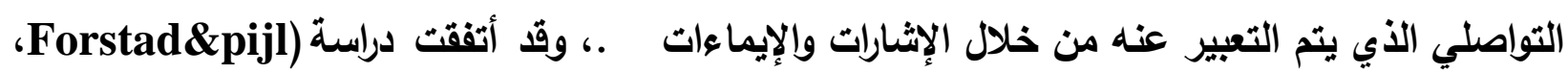

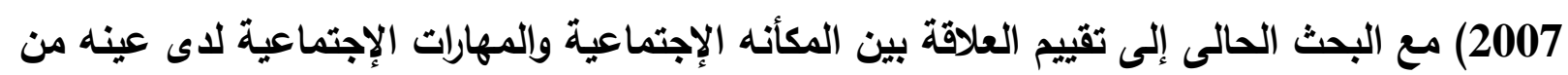

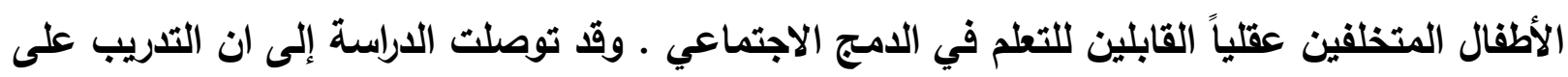

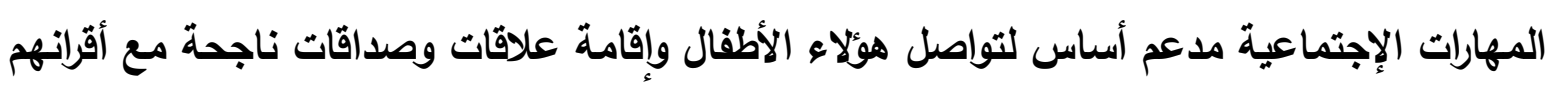

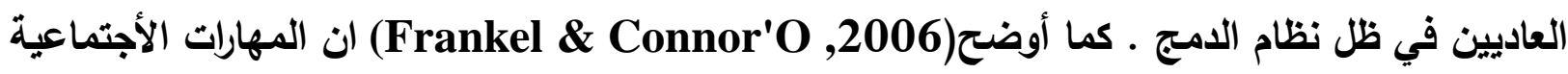
هى تلك القدرات الخاصة التي تجعل الطقل قادراً على الأداء بكفاية في أعمال اجتماعية خاصة بتبادل العلاقات الثخصية مع الآخرين وأداء الأعمال من خلال المواقف المختلفة. 


\section{مراجع العحث}

\section{أولا : المراجع العربية :}

1 - إبراهيم الزهيري (2007): تربية المعاقين والموهويين ونظم تعليمهم، ط1، القاهرة : دار الفكر العربي. r - أحمد نبوي، خالد عبد الحميد (2012) • " الاتجاه نحو دمج المعاقين سمعيا بالتعليم الجامعي، " الملتقي الثاني عشر للجمعية الخليجية للإعاقة، سلطنة عمان، مسقط، مايو 2012. r - - أسماء السحيمي وفودة محمد (2009): تنمية السلوك الاجتماعي لطفل ما قبل المدرسة. الإسكندرية، دار الجامعة الجديدة.

ع - - السيد عبد القادر شريف ( 2006): دمج الأطفال المعاقين ذهنياً القابلين للتعلم مع أقرانهم العاديين في رياض الأطفال وتتمية بعض مهاراتهم الاجتماعية ، المؤتمر السنوي لكلية رياض الأطفال (التربية الوجداتية للطفل)، جامعة القاهرة ، 2006، 209. ه - السيد عبد القادر شريف (2014): مدخل إلى التربية الخاصة ، القاهرة، دار الجوهرة. צ - القرار الوزاري للمدمج (2009): وزارة التربية والتعليم. V - أماني عبد الفتاح ( 2012): مهارات الاتصال والتفاعل والعلاقات الإنسانية ، القاهرة ، مكتبة الأنجلو المصرية.

^ - أماني عبد الفتاح. (2012).مهارات الإتصال والتفاعل والعلاقات الإنسانية، مكتبة الأنجلو المصرية 9 - أمل محمد زكريا ( 2015): برنامج لتحسين التواصل بين الأطفال العاديين والمعاقين ذهنياً للمعلم في روضات الامج ، رسالة ماجستير ، جامعة القاهرة ، كلية رياض الأطفال. • 1 -أمل محمد زكريا القاضي(2015): برنامج لتحسين التواصل بين الأطفال العاديين والمعاقين ذهنيًا القابلين للتعلم في روضات الامج، رسالة ماجستير، كلية رياض الأطفال، جامعة القاهرة. 1 أ-مبرة طه بخش(2002): فاعلية برنامج تدريبي مقترح لأداء بعض الأنشطة المتنوعة علي تنمية المهارات الاجتماعية للأطفال المعاقين عقليًا القابلين للتعلم، مجلة العلوم التريوية، 1 (1)، 129-157. r T أنسي محمد أحمد قاسم .(2005). علم نفس التعلم . مركز الأسكندرية للكتاب . r إيهاب الببلاوي (2005): اضطرابات التواصل ، القاهرة ، مكتبة الأنجلو المصرية. ؛ 1 -بطرس حافظ بطرس (2009): سيكولوجية الدمج في الطقولة المبكرة ، عمان ، دار المسيرة للنشر. 10 1 ا 1 -حصة محمد ال مساعد، احلام عبد السميع العقباوي.(2011). مهارات الإتصال والتفاعل. القاهرة. عالم الكتب . IV - سهير محمد سلامة شاش: (2007). إضطرابات التواصل (التثخيص - الأسباب - العلاج) القاهرة. دار زهراء الشرق

1 ا مشيماء محمد عبد الله محمد.(2010).أبعاد الأكاء الوجداني لاي عينه من المعاقين عقلياً في ضوء الامج والعزل، ماجستير، قسم العلوم النفسية، كلية رياض الأطفال، جامعة القاهرة . 9 ا مشيماء محمدعبد الله محمد (2010):أبعاد الأكاء الوجدانى لاى عينة من المعاقين عقليا فى ضوء نظامى الامج والعزل : رسالة ماجستير غير منشورة، كلية رياض الأطفال، جامعة القاهرة. 
• • - - طنطاوي، حسام عباس خليل : (2009). فعالية الأنشطة اللاصفية في تنمية بعض المهارات الإجتماعية

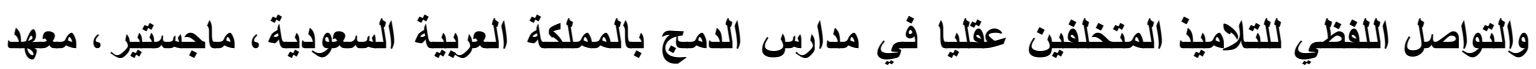
الاراسات والبحوث التريوية قسم رياض الأطفال والتعليم الابتدائي، جامعة القاهرة ا Y -عبد العليم شرف (2008): طرق تعليم المهارات الأساسية والاجتماعية للمعاقين عقليًا ، عالم الكتب ، القاهرة.

r Y - Mعبد الفتاح صابر (2002): التربية الخاصة لمن لماذا كيف ، القاهرة ، دار الكتب المصرية. r r - -عبد المطلب القريطي (2001): سيكولوجية ذوي الاحتياجات الخاصة وتربيتهم ، ط3، القاهرة : دار الفكر العربي. ع r - ع عبدالله اسماعيل الصوفي(2000):معجم التقتيات التريوية، عمان، الأردن. ه r -عزة خليل (2011) ـ علم نفس اللعب في الطفولة المبكرة بين النظرية والتطبيق ـ القاهرة ـ دار الفكر العربي

צ r - -عزت عبد الرحمن مصطفى ( 2011): فاعلية برنامج لتعلم التواصل اللفظي في تنمية الانتباه والإدراك السمعي والبصري لدى الأطفال المعاقين عقلياً للتعلم ، رسالة دكتوراه ، قسم علم النفس التربوي ، معهد الاراسات التربوية ، جامعة القاهرة.

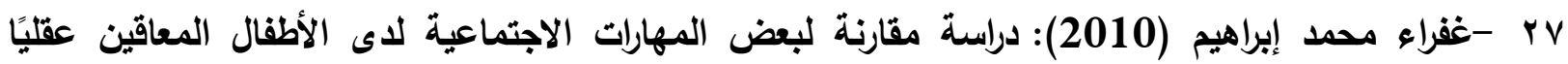

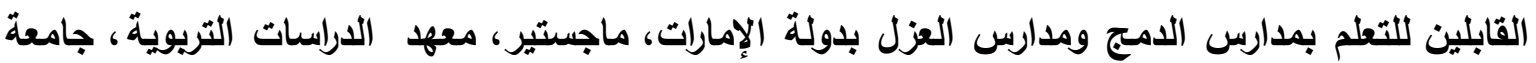
القاهرة.

^r - فريد الخطيب، ( 2002) • واقع خدمات مديرية التربية الخاصة، وزارة التربية والتعليم في الاردن، ورقة

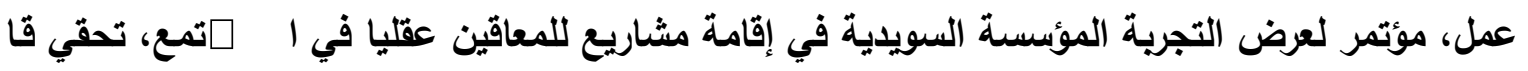
لمبدأ تكافؤ الفرص الذي تتبناه هيئة الأمم المتحدة. فندق راديسون ساس، عمان، الاردئ. q ج - فلافيا محمد عثمان.(2012).برنامج إرشادي لمعلمات رياض الأطفال لتنمية التواصل اللفظي والاجتماعي وخفض السلوك العدواني لطفل الروضة، دكتوراه، قسم العلوم النفسية وكلية رياض الأطفال وجامعة القاهرة

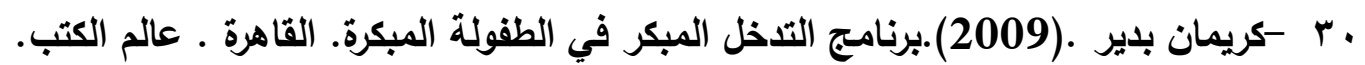
اس -كوليت دريفت (2004): متطلبات التعليم المبكر لأطفال ذوي الاحتياجات الخاصة، ترجمة: خالد الغامري ، القاهرة ، دار الفاروق للنشر والتوزيع ، القاهرة.

r r - ماجدة عبيد ( 2000): تعليم الأطفال ذوي الاحتياجات الخاصة (مدخل التربية الخاصة) ، عمان ، دار الصفاء.

r r -مارتن هنلي ، رويرتارامزي ( 2004): خصائص التلاميذ ذوي الاحتياجات الخاصة واستراتيجيات تدريبهم ، تعريف جابر عبد الحميد جابر ، دار الفكر العربي ، القهرة. ع r - محمد العجمي (2006): فلسفة التربية الخاصة بالمعوقين، عالم الكتب، القاهرة. هـ -محمد بلال الجيوسي (2002). "انت وأنا " مقدمة في مهارات التواصل الإنساني " .الرياض ـ مكتبة التربية العربي لدول الخليج · 
צr -محمد بلال الجيوشي ( 2002): أنت وأنا ... مقدمة في مهارات التواصل الإنساني ، الرياضة ، مكتبة

$$
\text { التدريب العربي لدول الخليج. }
$$

rv - F rvمد كامل (2003): أخصائي النطق والتخاطب ومواجهة اضطرابات اللغة عند ط ، القاهرة ، مكتبة ابن

^ץ -محمد مقداد (2008): إعداد معلمي التلاميذ العاديين للتكفل بذوي الاحتياجات الخاصة في ضوء أساليب الامج ، الإسكندرية ، المكتب الجامعي الحديث. q ب -ممدوح عبد الرحيم الجفري ، هناء صلاح عبد الحليم (2011):البيئة التربوية ودمج غير العاديين بمؤسسات رياض الأطفال (إستراتيجيات الإدارة)، دار المعرفة الجامعية، الإسكندرية. • ـ -منى جاد ، نجلاع السيد (2008): الأصول الاجتماعية للتربية.

اء ـ -منى محمد علي جاد (2004): التربية البيئية في مرحلة الطقولة وتصنيفها ، دار المسرة ، القاهرة. r צ -منى محمد علي جاد (2007): مناهج رياض الأطفال ، عمان ، دار المسرة. بـ - -منى محمد علي جاد ( 2014): الاتجاهات التربوية المعاصرة لتربية طقل الروضة ، مكتبة الحصري، القاهرة.

؟ ؛ -منى محمد علي جاد (2014): التربية الوالدية للأطفال ، مكتبة الحصري ، القاهرة. هـ - مني محمد علي جاد، نجلاء السيد. (2008) ـ الأصول الأجتماعية للتربية، القاهرة צ ؛ -هدى الناشف (2005): قضايا معاصرة في تربية الطقولة المبكرة ، القاهرة ، دار الفكر العربي.

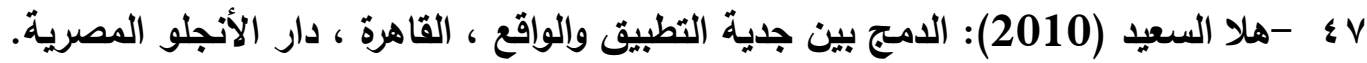
^ـ -وزارة التربية والتعليم (2009): قرار وزير رقم 94، بشان قبول التلاميذ ذوي الإعاقة البسيطة بمدارس التعليم العام.

9 - يوسف قطامي .(2000). نمو الطقل المعرفي واللغوي . عمان المملكة الأردنية الهاشمية ـ الأهلية للنشر والتوزيع •

ثانياً: المراجع الأجنبية:

50-John, Angela E,.(2010). Comprehension of the communictive intent behind pointing and gazing gestures by young childrn illiams syndrome or down syndrome.journal of speech, languge, ad hering resarch .vol.53(4), aug 2010 ,pp.950-960

51-Cottrell, S. (1999): The study skills handbook, london: Macmillan Press Ltd.

52-Dessmontet,R. (2012): effect of inclusion on academic achievement an adaptive behavior of children with intellectual disabilities. journal of intellectual disabilities research. Vol. 56(6), jun2012,pp.579-587.

53-Dolva,Anne-stine,.(2011). Facilitating peer interaction-support to children with down syndrome $n$ mainsrem schools . europen journal of spcial needs education. Vol.26(2),may2011,pp.201-213. 
54-Frankel, F. \& O'Connor, M. J. (2006). A Controlled Social Skills Ttraining for Children with Fetal Alcohol Spectrum Disorders. J. of Consulting and Clinical Psychology, 24, 9, 634-648.

55-Frostad, p\&pijl,S,J.(2007).Does being friendly help in meking Friends ? The relation between the social position and social skills of pupils with special needs in mainstream education. European Journal of Special Needs Educstion, 22.(1):15-30

56-Hunies $T$, pretzlik $U$, and Olsson $J$ (2009) : Children's social relationship in mainstream schools. Deafness and education international, v3,n3,pp. 123-136.

57-Punch, R. and Hyde, M. (2005): The Social Participation and Career Decisionmaking of Hard-of Hearing adolescents in Regular Classes. Deafness and education international,v7.n1,pp.122-138.

58-Stanton-Chapman,Tinal,.(2011). Prmoting turn-kingskill in preschool children with disabilities: the effects of peer-based social communication intervention Timler G. vogler - Elias \& Mcgill, K. (2007) .strategies For Promoting Generalication of social Communication Skills In Presonoolers And School Aged Children . Language Disordeds 27 (2) , 167 - 181 . 


\section{ملخص البحث}

"برنامج مقترح لتدريب الوالدين على اكساب الطقل المدمج بعض مهارات التواصل اللازمة للامج الاجتماعي مع الأطفال العاديين

$$
\text { الباحثة / حبيبة محمد صابر بركات }
$$

باحثة دكتوراه بكلية التربية للطقولة المبكرة - جامعة القاهرة

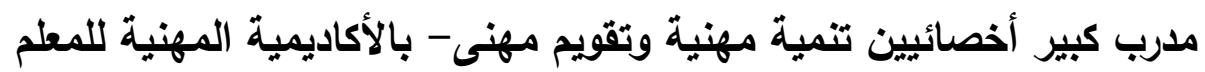

الملخص باللغة العربية

يهدف الححث الى التعرف على أثكال التواصل التى يمكن إكسابها لأولياء أمور الأطفال المدمجين ، وأعداد برنامج لتدريب الوالدين على إكساب الطقل المدمج بعض مهارات التواصل اللازمة للامجج

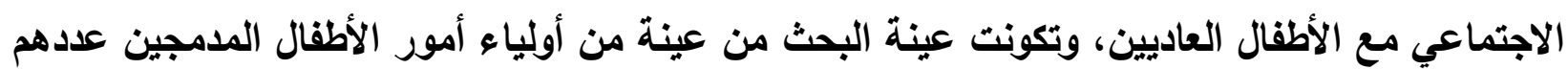

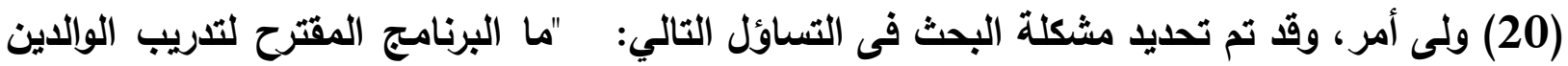

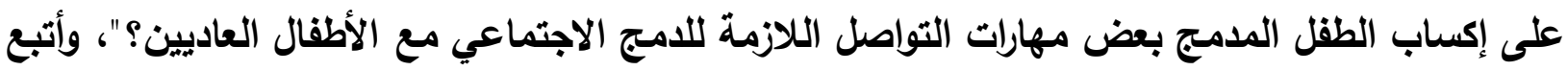

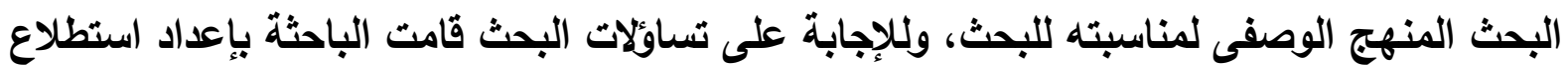

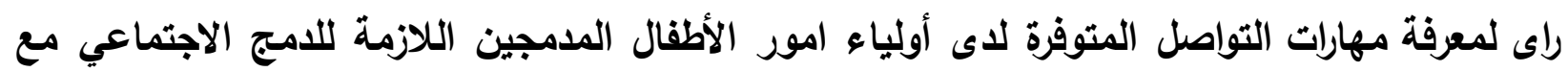

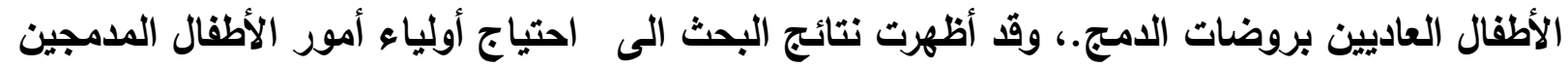

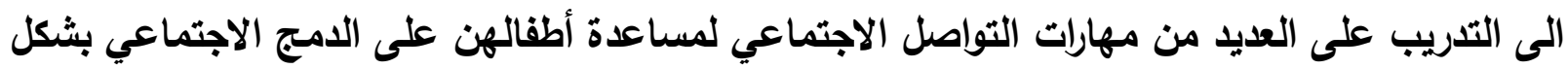
فعال مع الأطفال العاديين بروضات الدمج برياض الأطفال الى جانب التدريب على مهارات الاتصال والتواصل اللازمة للوالدين لإكساب أطفالهم بعض مهارات التواصل. الكلمات المفتاحية: الطقل الددمج، مهارات التواصل، الوالدين، الامبج الاجتماعي. 


\section{Abstract \\ "A proposed program to train parents on the child's built-in Achsab some of the communication skills necessary for social integration with ordinary children" \\ By \\ Researcher / Habiba Mohammed Saber Barakat \\ Researcher in the Faculty of Early Childhood Education - Cairo University \\ Senior Trainer Professional Development and Vocational Evaluation - Professional Academy of Teacher}

Summary of the Study:

The aim of the research is to identify the forms of communication that can be gained for the integrated children's parents, and to prepare a program for training parents on the child's built-in Achsab, some of the communication skills necessary for social integration with ordinary children., And the research sample consisted of a sample of (20) parents. The research problem was determined by the following question: "What is the proposed program for training parents on the child's IBSB with some communication skills necessary for social integration with ordinary children?" In order to answer the research questions, the researcher prepared a questionnaire to find out the communication skills of the parents of the integrated children who are required for social integration with ordinary children in the integration projects. The results of the research showed that the parents of the children are required to train To have many social communication skills to help their children integrate socially effectively with ordinary children through kindergarten integration. As well as training in communication skills necessary for parents to give their children some communication skills.

Keywords: Integrated Child, Communication Skills, Parenting, Social Integration. 